\title{
Redox Signaling Mediated by Thioredoxin and Glutathione Systems in the Central Nervous System
}

\author{
Xiaoyuan Ren,, ${ }^{1, *}$ Lili Zou, ${ }^{1,2, *}$ Xu Zhang,, Vasco Branco, Jun Wang, \\ Cristina Carvalho, ${ }^{3}$ Arne Holmgren, ${ }^{1}$ and Jun Lu ${ }^{4}$
}

\begin{abstract}
Significance: The thioredoxin (Trx) and glutathione (GSH) systems play important roles in maintaining the redox balance in the brain, a tissue that is prone to oxidative stress due to its high-energy demand. These two disulfide reductase systems are active in various areas of the brain and are considered to be critical antioxidant systems in the central nervous system (CNS). Various neuronal disorders have been characterized to have imbalanced redox homeostasis.

Recent Advances: In addition to their detrimental effects, recent studies have highlighted that reactive oxygen species/reactive nitrogen species (ROS/RNS) act as critical signaling molecules by modifying thiols in proteins. The Trx and GSH systems, which reversibly regulate thiol modifications, regulate redox signaling involved in various biological events in the CNS.

Critical Issues: In this review, we focus on the following: (i) how ROS/RNS are produced and mediate signaling in CNS; (ii) how Trx and GSH systems regulate redox signaling by catalyzing reversible thiol modifications; (iii) how dysfunction of the Trx and GSH systems causes alterations of cellular redox signaling in human neuronal diseases; and (iv) the effects of certain small molecules that target thiol-based signaling pathways in the CNS.

Future Directions: Further study on the roles of thiol-dependent redox systems in the CNS will improve our understanding of the pathogenesis of many human neuronal disorders and also help to develop novel protective and therapeutic strategies against neuronal diseases. Antioxid. Redox Signal. 27, 989-1010.
\end{abstract}

Keywords: redox signaling, thioredoxin, glutaredoxin, glutathione, CNS, thiol-targeted compounds

\section{Introduction}

$\mathbf{T}$ HE THIOREDOXIN SYSTEM, which comprises thioredoxin (Trx), thioredoxin reductase (TrxR), and NADPH, and the glutathione system, which comprises NADPH, glutathione reductase (GR), and glutathione (GSH), are two cellular disulfide reductase systems. Trx is a ubiquitous small $(12 \mathrm{kDa})$ enzyme with a -CGPC- motif within its active site. Trx was originally identified in Escherichia coli as an electron donor for ribonucleotide reductase (RNR) $(109,125)$. The structure of Trx is known as the Trx fold; it contains four $\beta$-strands in the core and $\alpha$-helices surrounding the central $\beta$-sheets (127). In mammalian cells, there are three isoforms of Trx: Trx 1 in the cytosol, Trx 2 in mitochondria, and a testis-specific Trx. As part of the Trx family, these proteins contain at least one Trx fold in their structure. Trxs and other Trx superfamily proteins are widely expressed in different regions of the mammalian central nervous system (CNS) $(7,179)$. Reduced Trxs are powerful reductases with a relatively broad spectrum of substrates and act via a disulfide-dithiol exchange mechanism to catalyze the conversion of disulfide bonds into thiols with high efficiency. The disulfides in oxidized Trxs are converted to thiols

\footnotetext{
${ }^{1}$ Division of Biochemistry, Department of Medical Biochemistry and Biophysics, Karolinska Institutet, Stockholm, Sweden.

${ }^{2}$ Translational Neuroscience and Neural Regeneration and Repair Institute/Institute of Cell Therapy, The First Hospital of Yichang, Three Gorges University, Yichang, China.

${ }^{3}$ Research Institute for Medicines (iMed.ULisboa), Faculty of Pharmacy, Universidade de Lisboa, Lisboa, Portugal.

${ }^{4}$ School of Pharmaceutical Sciences, Southwest University, Chongqing, China.

*These authors contributed equally to this work.
} 
by consumption of NADPH through redox cycling via TrxRs (Fig. 1) $(84,85)$. Corresponding to the Trxs, there are three forms of mammalian TrxRs: cytosolic TrxR1, mitochondrial TrxR2, and testis-specific TrxR3. TrxR3 is also referred to as Trx and glutathione disulfide reductase (TGR) due to its ability to reduce Trx and glutathione disulfide (GSSG) $(121,151)$. Mammalian TrxRs are dimeric flavoproteins with a molecular weight of $\sim 115 \mathrm{kDa}$. The structure of mammalian TrxR is similar to GR, with a -CVNVGC- active site motif in its Nterminus, whereas TrxRs contain a 16 amino acid residue extension with a selenocysteine ( $\mathrm{Sec}, \mathrm{U})$-containing -GCUCactive site motif in the C-terminus (170). The Sec residue is critical for TrxRs to exert their reductase activity (224). The activity of TrxR in rat brain can be maintained at a certain level under severe selenium (Se)-deficient conditions, while other selenoproteins, including glutathione peroxidase (GPx), lose the majority of their activity, indicating that TrxR is very important in the brain (123).

The GSH-glutaredoxin (Grx) system is another disulfide reduction system in cells. Grxs are part of the Trx protein family. As well as a disulfide-dithiol exchange mechanism, Grx can catalyze the reduction of substrates via a monothiol mechanism. There are two major forms of Grx: Grx1, present in the cytosol, and Grx2, located in the mitochondria and nuclei of mammalian cells (124). Grx1 accepts electrons from GSH, while Grx 2 can obtain electrons from both GSH and TrxR2 (91). GSH is the most abundant small molecular thiol and is present at a high concentration in the brain $(\sim 1-3 \mathrm{mM})$. Generally, it is thought that astrocytes produce a high level of $\mathrm{GSH}$, which is released and degraded extracellularly and then subsequently used by other neurons for GSH synthesis (54).

Trx and GSH systems are the two major thiol-dependent antioxidant mechanisms in cells and also participate in DNA synthesis and repair as an electron donor for RNR and protein methionine sulfoxide reduction by providing electrons to methionine sulfoxide reductase (MSR); these processes are described in detail in previous reports $(86,111,151)$. This review will focus on the roles of Trx and GSH in regulating redox

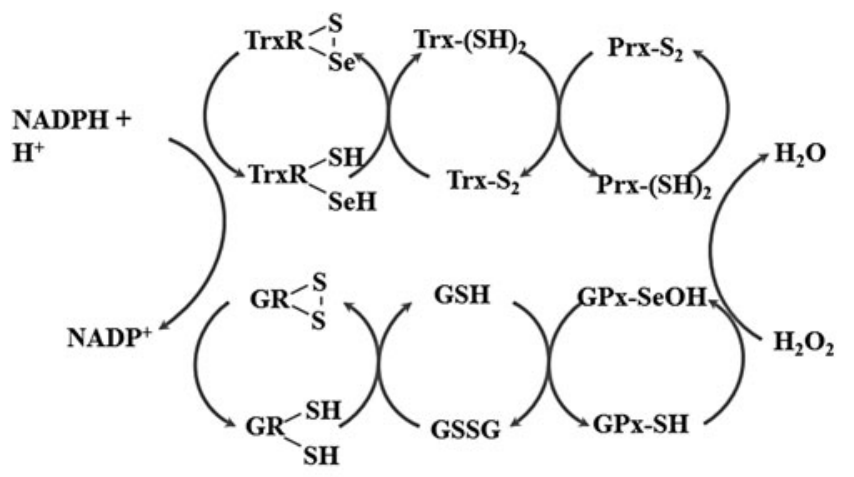

$$
\mathrm{NADPH}+\mathrm{H}^{+}+\mathrm{H}_{2} \mathrm{O}_{2} \underset{\text { GR/GSH/GPx }}{\stackrel{\operatorname{TrxR} / \mathrm{Trx} / \mathrm{Prx}}{\underset{\mathrm{NADP}}{ }}} \mathrm{N}+2 \mathrm{H}_{2} \mathrm{O}
$$

FIG. 1. Two thiol-dependent redox systems. The disulfides in oxidized Trxs/GSH are converted to thiols by consumption of NADPH through redox cycling via TrxRs/ GRs. GSH, glutathione; GR, glutathione reductase; Trx, thioredoxin; TrxR, thioredoxin reductase. signaling in the CNS and the effects of redox-active compounds in neuronal disorders via the Trx and GSH systems.

\section{Production of Reactive Oxygen Species in Neuronal Systems}

Reactive oxygen species (ROS), including superoxide $\left(\mathrm{O}_{2}{ }^{\bullet-}\right)$, hydrogen peroxide $\left(\mathrm{H}_{2} \mathrm{O}_{2}\right)$, and hydroxyl radical $\left(\mathrm{OH}^{\bullet}\right)$, are produced via the leaking of electrons from the mitochondrial respiration chain or through certain enzymatic reactions, such as NADPH oxidase (NOX) and monoamine oxidase (MAO) under physiological conditions (Fig. 2). Although the brain constitutes only $2 \%$ of total body weight, it consumes $\sim 20 \%$ of the total oxygen used by the body. Thus, the high level of glucose metabolism and oxygen consumption continually produce excessive ROS. Besides this, several other factors make brain tissue more susceptible to oxidative stress than other tissues (76): the brain is highly enriched with lipid and about $35 \%$ of brain lipids are polyunsaturated fatty acids, which are important for neuronal functions, but sensitive to ROS attack (17); glutamate receptor-mediated excitotoxicity can undergo positive feedback with ROS and cause neuron cell death; high levels of metal ions in the brain can catalyze more toxic free radical production; loss of trophic support can induce activation of NOX; microglia, the resident macrophagetype cells in the brain, can be activated during immune response by cytokines leading to ROS generation and the subsequent expression of inducible nitric oxide synthase (iNOS), which produces nitric oxide (NO).

To maintain redox balance, organisms are equipped with various antioxidant enzymes, including superoxide dismutase (SOD), catalase (CAT), GPx, and peroxiredoxin (Prx), and small antioxidants, such as GSH, coenzyme Q, vitamin C, and E (Fig. 3). The antioxidant capacity in most areas of the brain is modest; in particular, there is very low, if any, CAT expression in brain cell mitochondria $(76,180)$. Human neuronal disorders, such as neurodegenerative diseases, are closely linked to oxidative stress, which is defined as an imbalanced status whereby ROS levels overwhelm antioxidants. However, recently developed methods have provided useful tools to study the role of ROS in a more physiologically relevant context. For example, development of the HyPer probe has enabled real-time imaging of ROS in living systems (24), and the use of Rhodotorula gracilis D-amino acid oxidase allows precise manipulation of ROS production in cells (80). With the help of these new techniques, the definition of oxidative stress has evolved during the last decades, and oxidative stress is now preferably considered to be the disruption of redox signaling and regulation (95). Therefore, it is suggested that the effects of ROS in the brain are most likely mediated through a redox signaling process rather than extensive nonspecific cellular damage. The redox environment is usually determined by several local factors, such as colocalization of oxidant/antioxidant enzymes, the ratio of oxidizing/reducing equivalence, the presence of metal ions, cellular compartmentalization, and so on.

\section{Redox Signaling Regulation in CNS by Trx and GSH Systems}

Trx and related antioxidant enzymes are specifically localized to different subcellular organelles in neuronal and glial cells and locally control redox signaling. The Trx1 system, 


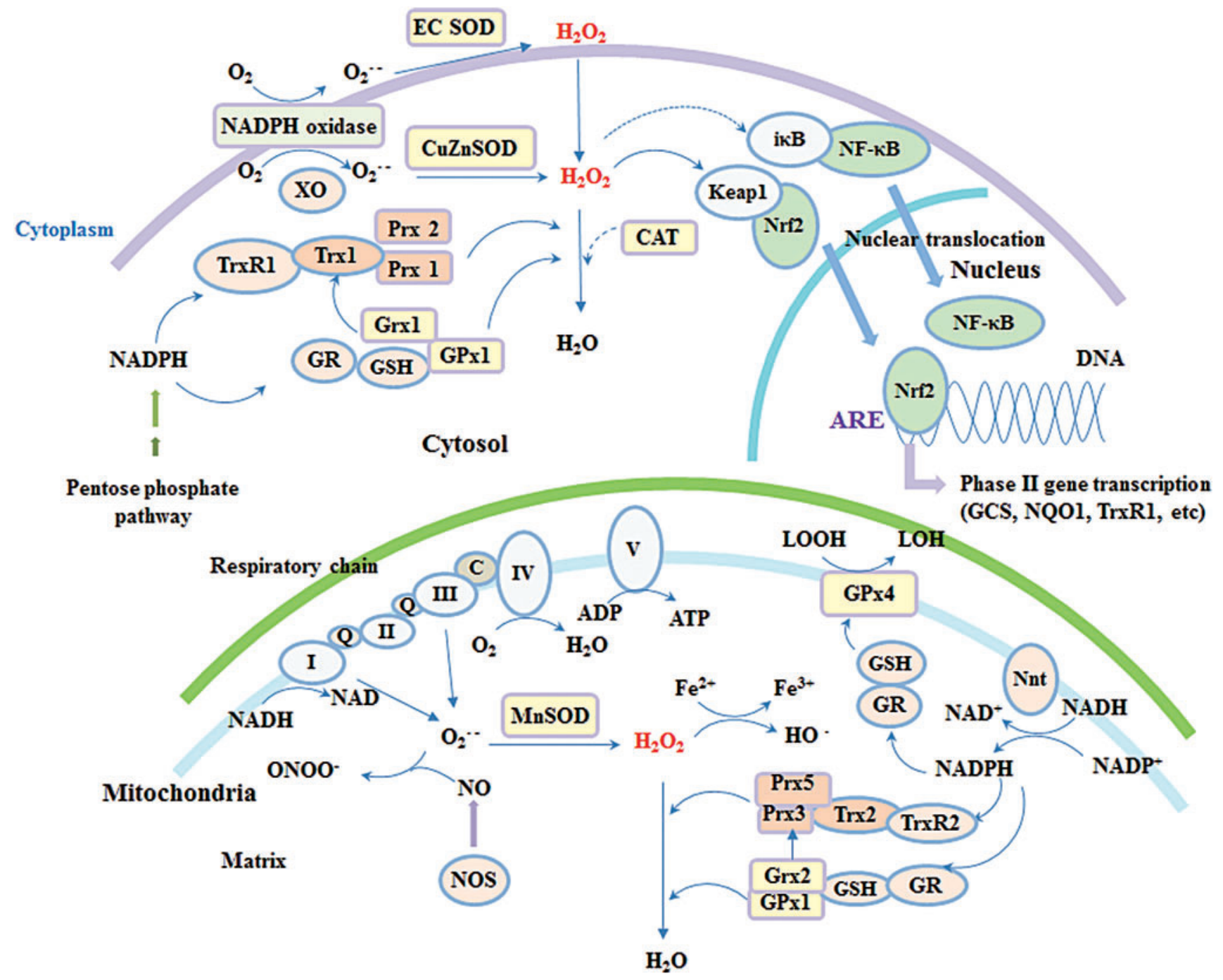

FIG. 2. Production of ROS and redox signaling regulation in the neuronal system by Trx and GSH/Grx systems. ROS are produced via the leaking of electrons from the mitochondrial respiration chain or through some enzymatic reactions under physiological conditions. Trx and GSH/Grx systems are present specifically in different subcellular organelles in neuronal and glial cells and locally control redox signaling. Grx, glutaredoxin; ROS, reactive oxygen species. To see this illustration in color, the reader is referred to the web version of this article at www.liebertpub.com/ars

coupled with Prx1/2 and MSR, and the GSH-Grx1 system, coupled with GPx1, regulate redox signaling in the cytosol and nucleus. The Trx 2 system, coupled with Prx3/5 and MSR, and the GSH-Grx2 system, coupled with GPx1/4, regulate the mitochondrial redox environment and signaling (Fig. 2) (122). In addition, TrxR1/Trx1 are also present in neuronal synaptic vesicles (160). Generally, the Trx and GSH systems are thought to work in parallel, and in many cases, crosstalk occurs between these two systems, where components of one system serve as a backup for the components of the other $(56,57,221)$. Moreover, in the mitochondrial matrix, both Trx 2 and Grx 2 can transfer electrons to $\mathrm{Prx} 3$ to reduce $\mathrm{H}_{2} \mathrm{O}_{2}$ (77).

\section{Regulation of $\mathrm{H}_{2} \mathrm{O}_{2}$ metabolism via the $\mathrm{Trx} / \mathrm{Prx}$} and GSH/GPx systems

Prx, GPx, and CAT are the three types of antioxidant enzymes that catalyze the decomposition of $\mathrm{H}_{2} \mathrm{O}_{2}$ with high efficiency (122). These enzymes can scavenge $\mathrm{H}_{2} \mathrm{O}_{2}$ at a reaction rate of $10^{7}-10^{8} M^{-1} \mathrm{~s}^{-1}$, whereas the direct reaction rate of GSH with $\mathrm{H}_{2} \mathrm{O}_{2}$ is only $0.89 M^{-1} \mathrm{~s}^{-1}$ (207). Given the notable absence of CAT expression in brain mitochondria, the concentration of CAT in the brain is estimated at $1.2 \mu M$, which is $\sim 50$ times less than its level in the liver (154), whereas the Prx 3 concentration in the brain is $\sim 60 \mu M$, Prx 5 is $20 \mu M$, and GPx 1 is $2 \mu M(44,184)$.

Mitochondria are the main sites of superoxide and $\mathrm{H}_{2} \mathrm{O}_{2}$ production (138). About $0.5-2.0 \%$ of electrons leaked from mitochondrial respiration are converted into superoxide. Mitochondrial SOD2 can catalyze the conversion of superoxide to $\mathrm{H}_{2} \mathrm{O}_{2}$, a well-known signaling messenger (185). The rate of $\mathrm{H}_{2} \mathrm{O}_{2}$ production using NAD-linked substrates in the brain is $50-70 \mathrm{pmol} / \mathrm{min} / \mathrm{mg}$ mitochondrial protein. Interestingly, mitochondria can scavenge exogenous $\mathrm{H}_{2} \mathrm{O}_{2}$ at a rate of $9-12 \mathrm{nmol} / \mathrm{min} / \mathrm{mg}$ mitochondrial protein in a respiration- and substrate-dependent manner, which is 100 times higher than the $\mathrm{H}_{2} \mathrm{O}_{2}$ production rate. Thus, mitochondria act as a cellular source and also as a sink of $\mathrm{H}_{2} \mathrm{O}_{2}(6,184)$. 


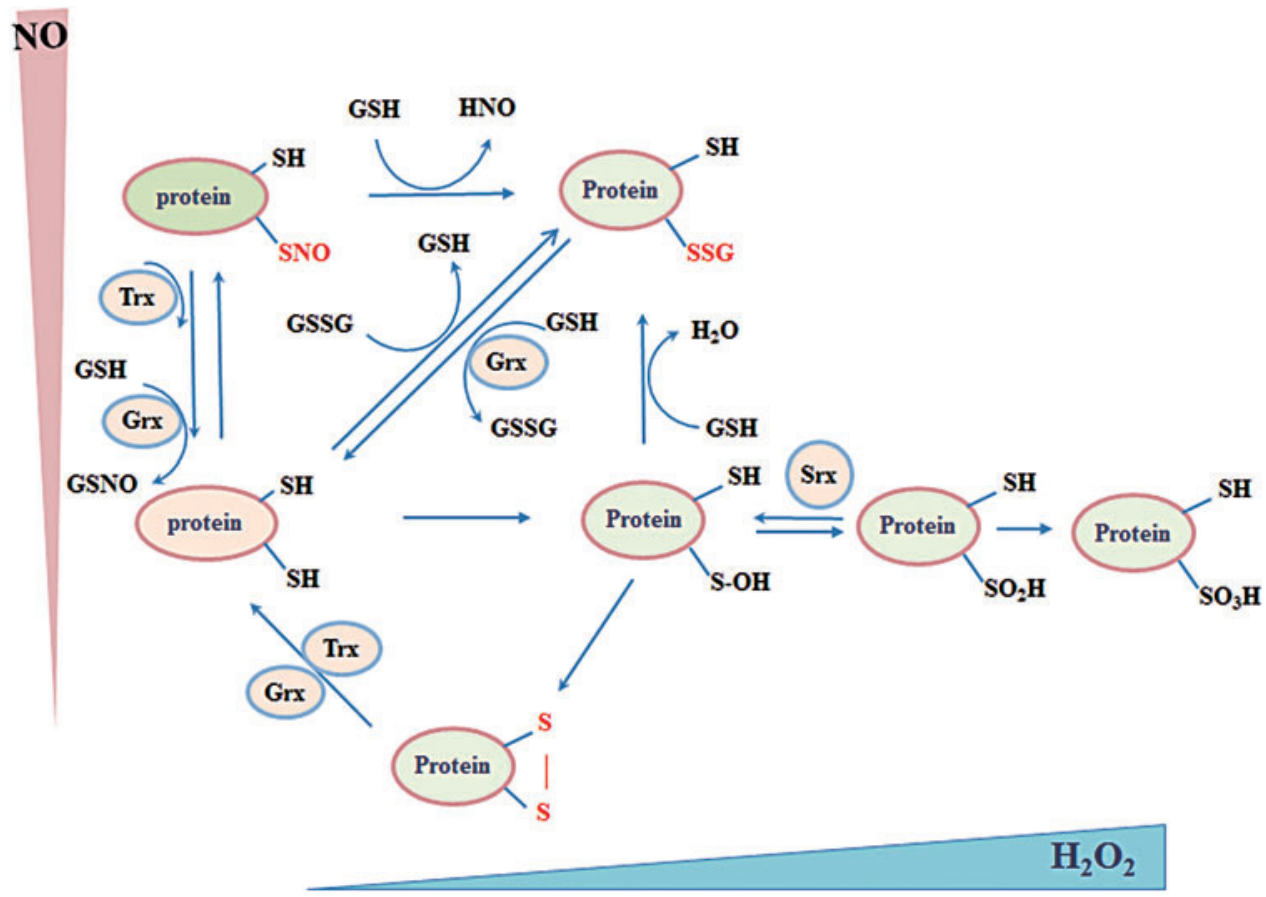

FIG. 3. Different thiol modifications regulated by Trx and GSH systems. Cysteines within proteins can be modified by $\mathrm{H}_{2} \mathrm{O}_{2}$ into sulfenic acid (-SOH), sulfinic acid $\left(-\mathrm{SO}_{2} \mathrm{H}\right)$, sulfonic acid $\left(-\mathrm{SO}_{3} \mathrm{H}\right)$, or disulfide (-S-S-). Nitric oxide can react with thiols to form S-nitrosylation (-SNO) and GSSG can form Sglutathionylation (-SSG) with reactive thiols. Trx and GSH systems participate in reduction of many of these thiol modifications. $\mathrm{H}_{2} \mathrm{O}_{2}$, hydrogen peroxide. To see this illustration in color, the reader is referred to the web version of this article at www.liebertpub. com/ars
Several studies have highlighted the essential role of the mitochondrial Trx system in counteracting ROS in the brain, with its importance potentially due to the lack of CAT expression. Inhibition of mitochondrial TrxR2 by auranofin was demonstrated to diminish the $\mathrm{H}_{2} \mathrm{O}_{2}$ scavenging capacity of mitochondria, whereas this was not affected by uncoupling of mitochondria, phosphorylation of added ADP, or the genetic ablation of GPx $1(53,184)$. Mitochondrial Trx/Prx couple was suggested to reduce $\mathrm{H}_{2} \mathrm{O}_{2}$ in a respiration-dependent manner. Nicotinamide nucleotide transhydrogenase (Nnt), which uses $\mathrm{NADH}$ and $\mathrm{NADP}^{+}$to generate NADPH, links the substrate requirement to mitochondrial $\operatorname{Trx} / \operatorname{Prx}$ as the ultimate electron donor for $\mathrm{H}_{2} \mathrm{O}_{2}$ removal. In a previous study, inhibition of Nnt decreased the NADPH level and impeded the Trx system's capacity to scavenge $\mathrm{H}_{2} \mathrm{O}_{2}$ in the brain, whereas inhibition of Nnt had no effects on $\mathrm{H}_{2} \mathrm{O}_{2}$ removal in liver mitochondria since it is independent of respiration as CAT is highly expressed in mitochondria from liver cells (119).

\section{Reversible regulation of protein thiol modification}

A large part of ROS/reactive nitrogen species (RNS)mediated signal transduction relies on modifications of cysteine thiol $(-\mathrm{SH})$ within proteins. Irreversible thiol modification (sulfonic acid, $-\mathrm{SO}_{3} \mathrm{H}$ ) has been considered a hallmark for various pathological conditions and usually leads to permanent functional loss and degradation of the protein. Reversible thiol modifications, such as S-nitrosylation (-SNO), S-sulfenylation (sulfenic acid, -SOH), S-glutathionylation (-SSG), disulfide formation (-S-S-), S-sulfhydration (-S-SH), and sulfinic acid $\left(-\mathrm{SO}_{2} \mathrm{H}\right)$, are involved in redox signaling (Fig. 3).

Several properties allow thiols to act as signal switches. First, thiols are susceptible to ROS/RNS challenge that lays a foundation for its sensitivity. Second, in different local environments, thiols exhibit different reactivity, which gives them selectivity (62). Last, most thiol modifications are re- versible, which provides flexibility for sophisticated signaling regulation. Thus, great efforts have been made to identify proteins with functional cysteines and understand the regulation of reversible thiol modification in neuronal systems.

S-nitrosylation. NO can be produced endogenously by NOSs, which utilize L-arginine amino acid, oxygen, and NADPH as the electron donor. There are three NOS isoforms identified in mammals, which are named mainly depending on their tissue distribution. Neuronal NOS (nNOS) was first found in the CNS (131). Endothelial NOS (eNOS) is mainly expressed not only in endothelial cells from blood vessels (161) but also in cells from other tissues, such as platelets, smooth muscle cells, hepatocytes, and certain types of neuronal cells (65). The activity of both nNOS and eNOS is regulated by $\mathrm{Ca}^{2+}$ and calmodulin. In contrast to the other two isoforms, iNOS is regulated in a $\mathrm{Ca}^{2+}$-calmodulin-independent manner and is not constitutively expressed in cells. Instead, iNOS expression and NO production can be induced dramatically via stimulation from various factors, such as inflammatory cytokines and lipopolysaccharides. This property is used by immune cells, including macrophages and glial cells, to fight against invading microbes (26). During the last two decades, NO was also identified to be involved in S-nitrosylation, a post-translational modification (PTM) that directly adds an NO moiety to a reactive thiol of cysteine to form S-nitrosothiols (SNOs). Similar to other PTMs such as phosphorylation, S-nitrosylation can alter protein activity, interactions, and redox status and plays an important role in physiological and pathological conditions (5).

S-nitrosylation in neuronal system. In the neuronal system, NO functions as a neurotransmitter, mainly via the classical NO-soluble guanylate cyclase (sGC)-cyclic guanosine monophosphate (cGMP) pathway (69). In addition, accumulating evidence has shown that NO also acts through S-nitrosylation, which can be both beneficial and detrimental. 
S-nitrosylation can promote neuron survival by targeting different proteins. For example, overactivation of the Nmethyl-D-aspartate (NMDA) glutamate receptors triggers neuron excitotoxicity, which is characterized by uncontrolled cellular calcium influx and cellular damage. NO produced by nNOS can nitrosylate specific thiols within the NR1 and NR2 subunits of NMDA receptors and negatively modulate $\mathrm{Ca}^{2+}$ influx (116). Serine racemase, which catalyzes the formation of D-serine, the coagonist of NMDA receptors, can also be Snitrosylated and inhibited by nNOS-produced NO (141). Both mechanisms protect neurons from excitotoxicity. Moreover, nitrosylation of the active site cysteine in caspases, the essential executers of programmed cell death, inhibits their activity and therefore plays a protective antiapoptotic role in neurons (191).

Several transcription factors are also regulated by Snitrosylation. NF- $\kappa \mathrm{B}$ has a central role in the immune system. The p50 (46) and p65 (99) subunits of NF- $\kappa \mathrm{B}$ are both reported to be S-nitrosylated by iNOS during immune responses. A recent study from Rottenberg and colleagues demonstrated that NO can protect the integrity of the blood-brain barrier (BBB) during trypanosome infection by S-nitrosylating the p65 subunit of NF- $\kappa \mathrm{B}$, thereby inhibiting penetration of immune cells and parasites into the brain (148). Hypoxiainducible factor 1 (HIF-1) is a master transcriptional factor that mediates the hypoxic adaption that is essential for neuronal development and survival. S-nitrosylation of cysteines in HIF$1 \alpha$ not only promoted its DNA binding (218) but also protected it from proteasomal degradation (114). The nuclear factor E2related factor 2 (Nrf2) binds to antioxidant response elements and initiates transcription of downstream targets to protect cells from oxidative and nitrosative stress. Under normal conditions, Nrf2 is sequestered by Klech-like ECH-associated protein 1 (Keap1) in the cytosol. Upon NO stimulation, Keap1 can be nitrosylated and release Nrf2, allowing its nuclear translocation and induction of antioxidant functions (200).

Excessive production of $\mathrm{NO}$ and aberrant protein Snitrosylation are often related to pathological changes, especially in neurodegenerative diseases, such as Parkinson's disease (PD), Alzheimer's disease (AD), Huntington's disease (HD), and amyotrophic lateral sclerosis. Oxidative and nitrosative stress are risk factors for neurodegenerative diseases, and S-nitrosylation of antioxidant enzymes deteriorates the situation. Prx2 is predominantly expressed in mammalian neurons (172) and plays important roles in protecting neurons from oxidative damage by degrading $\mathrm{H}_{2} \mathrm{O}_{2}$ (104). Snitrosylation of critical cysteines (Cys51 and Cys172) in Prx2 inhibits its activity, and the level of nitrosylated Prx 2 was found to be elevated in the brain of PD patients (59).

Accumulation of misfolded proteins is often observed in the foci of neurodegenerative diseases. Protein disulfide isomerase (PDI), an important protein that regulates endoplasmic reticulum (ER) stress and is involved in protein quality control, was found to be nitrosylated and have reduced activity in sporadic PD and AD (199). Parkin is an E3 ubiquitin ligase that mediates protein degradation and prevents aggregation of misfolded proteins in neurons. Studies have shown that S-nitrosylation of parkin inhibited its activity and contributed to the pathological progression of PD (217). Autophagy is another important cellular mechanism for the degradation of misfolded and aggregated proteins. JNK/Bcl-2/Beclin 1 and IKK $\beta / \mathrm{AMPK} /$ mTORC 1 are two well-characterized pathways that regulate this process. In an HD model, accumulation of mutant huntingtin was found, and both JNK and IKK $\beta$ were found to be Snitrosylated and have diminished activities (173).

Uncontrolled cell death is another feature of neurodegenerative diseases and can be induced by S-nitrosylation of different molecules. The $\mathrm{X}$-linked inhibitor of apoptosis protein (XIAP), an E3 ligase, directly binds to several members of the caspase protein family, mediating their degradation, and therefore exerts a protective role in neurodegenerative diseases (83). XIAP was found to be S-nitrosylated and have lost caspase-binding ability in PD patients, which allows induction of the apoptosis cascade in PD (196). S-nitrosylation of GAPDH Cys150 was shown to promote its binding to Siah1 and enhanced the nuclear translocation of GAPDH-Siah1 complexes, which initiate the apoptotic pathway, contributing to neuronal cell death (78) (Fig. 4).

Neurons are more vulnerable to mitochondrial dysfunction due to their high-energy demand. In a $\beta$-amyloid protein $(\mathrm{A} \beta)$ induced AD model, excessive production of $\mathrm{NO}$ led to dynamin-related protein 1 (Drp1) nitrosylation. S-nitrosylated Drp1 resulted in exaggerated mitochondrial fission and fragmentation, which worsened the function of mitochondria (37). In addition, S-nitrosylation of mitochondrial complex I and complex IV was shown to suppress their activity in the respiratory chain and inhibit oxidative phosphorylation (41).

Taken together, these studies demonstrate that Snitrosylation is an on/off switch signal for the activities of various important proteins that mediate cell death. Through regulation of activities of these proteins, S-nitrosylation may determine neuronal cell viability and subsequently contribute to pathogenesis in neurodegenerative diseases.

S-nitrosylation regulated by Trx. The evolutionarily conserved active site -CXXC- motif in Trxs emphasizes the biological importance of their function. The thiol reduction activity of the Trx system has been intensively investigated during the last few decades and recent studies revealed that Trx is also an efficient denitrosylase. During S-denitrosylation, a cysteine at the active site of Trx may form an intermolecular disulfide with the substrate or be transnitrosylated as an intermediate. The resulting product is nitroxyl (HNO) or NO and oxidized Trxs that can be reduced by TrxR (22). Using a proteomic approach, a broad spectrum of nitrosylated proteins, including some discussed above, were identified as substrates of Trx (23).

It is worth noting that human Trx1 plays different roles in Snitrosylation regulation under different redox states. In addition to the two cysteines at the active site, human Trx 1 contains three structural cysteines, Cys62, Cys69, and Cys73, all of which can be nitrosylated in different contexts (206). However, so far, only Cys69 and Cys73 have been reported to be nitrosylated physiologically $(75,79)$. Nitrosylated Trx 1 acts as a transnitrosylase that can transfer the NO groups to target proteins, including caspases (136), Prx1, and others (210). The formation of active site disulfide or mutated active site cysteines is a prerequisite for the transnitrosylase activity of Trx 1 (209). Therefore, under different redox contexts, Trx 1 may act as a denitrosylase or a transnitrosylase; Trx 1-mediated regulation of apoptosis via caspase 3 is an example of this. Reduced Trx 1 and Trx2 denitrosylate S-nitrosylated caspase 3 in the cytosol and mitochondria and facilitate Fas-induced apoptosis, which is important not only for neuronal development but also 


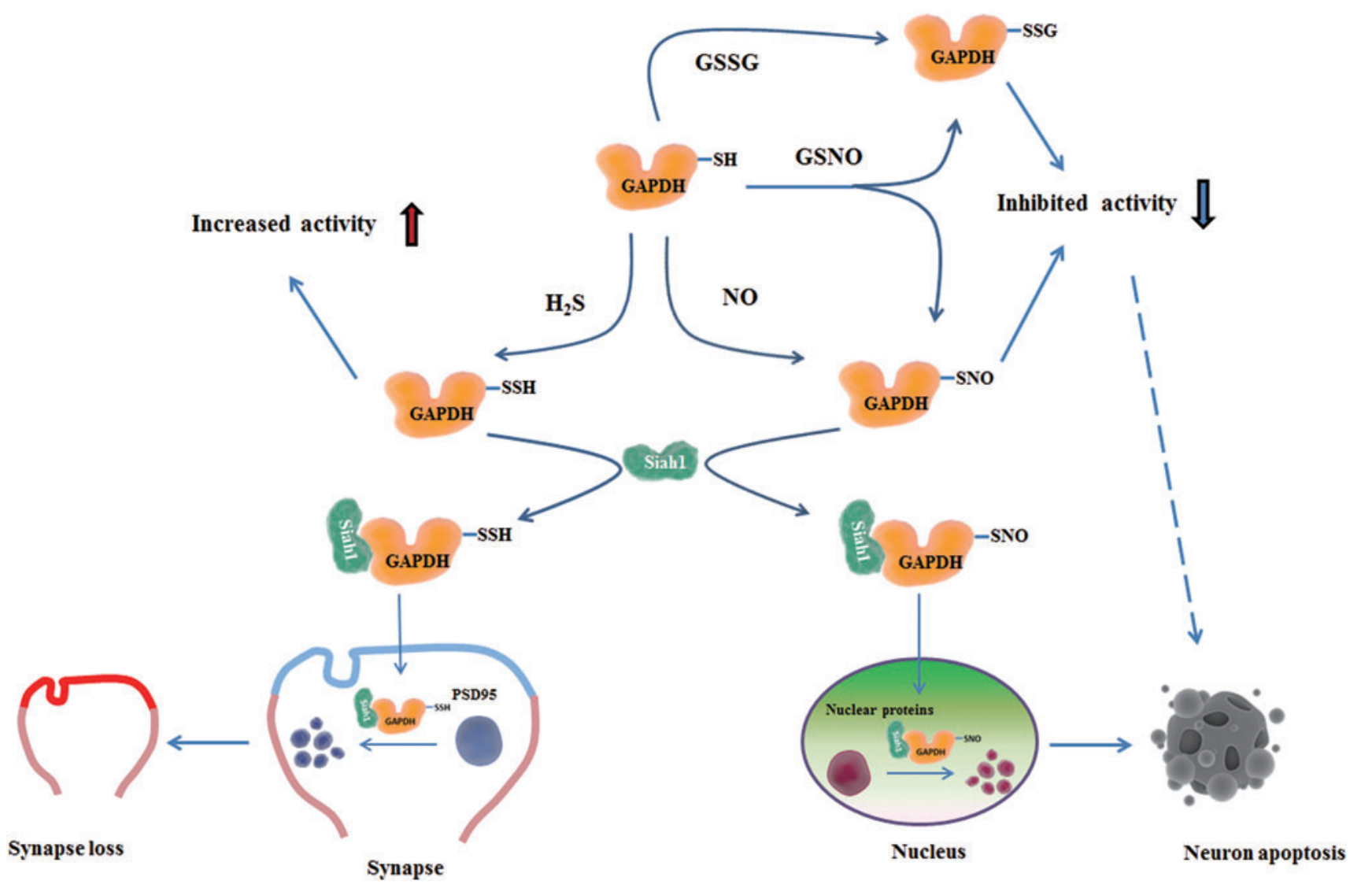

FIG. 4. Trx and Grx systems regulate thiol modifications of GAPDH and the effects on neuronal system. S-nitrosylation of GAPDH promotes its binding to Siah1, which degrades nuclear proteins and causes neuron apoptosis. Trx catalyzes denitrosylation of GAPDH. S-glutathionylation of GAPDH diminishes its activity and contributes to neurodegeneration. Grx can catalyze deglutathionylation of GAPDH. S-sulfhydration of GAPDH also enhances its binding to Siah1 and leads to degradation of PSD95 and synapse loss. Both Trx and Grx systems may play a role in desulfhydrating GAPDH. PSD95, postsynaptic density 95. To see this illustration in color, the reader is referred to the web version of this article at www.liebertpub.com/ars

contributes to pathological progression of neurodegenerative diseases (21). By contrast, nitrosylated Trx 1 is able to specifically transnitrosylate the catalytic cysteine of caspase 3 and reduce caspase activity, thus protecting neurons from stressinduced apoptosis (209) (Fig. 5). Using mass spectrum-based bioinformatic analysis in neuroblastoma cells, a study surprisingly found more than 40 proteins that were reversibly regulated via S-nitrosylation by Trx1 (210). Among these targets, GAPDH S-nitrosylation is reported to be closely associated with apoptosis (Fig. 4).

Thus, these results indicate that the Trx system is a sophisticated regulator of neuronal death that alters signaling via the $\mathrm{S}$-nitrosylation of proteins involved in the cell death process.

S-glutathionylation. GSH is the dominant low-molecularweight antioxidant in mammalian cells. The ratio between GSH and GSSG maintains the cellular redox potential and redox balance. Under oxidative or nitrosative stress, a decreased GSH/GSSG ratio can cause S-glutathionylation: a mixed disulfide formed between reactive thiols and GSH.

S-glutathionylation in neuronal system. Similar to Snitrosylation, protein S-glutathionylation is a well-controlled reversible PTM that alters protein functions in physiological conditions in the CNS. For example, $\mathrm{Ca}^{2+}$-dependent phosphorylation of ERK and $\mathrm{cAMP} / \mathrm{Ca}^{2+}$ response elementbinding protein (CREB) are required for synaptic plasticity. A study found that $\mathrm{H}_{2} \mathrm{O}_{2}$ increases glutathionylation and activation of ryanodine receptors (RyR), which release $\mathrm{Ca}^{2+}$, enhancing ERK and CREB phosphorylation, and helps maintain long-term potentiation (LTP) in the hippocampus (100).

However, abnormal protein S-glutathionylation has been considered to be a biomarker for neurodegenerative diseases. The pathological foci from patients with $\mathrm{AD}$ and $\mathrm{PD}$ have been found to contain aggregated GAPDH with inhibited activity and oxidative modifications (143). Analysis of inferior parietal lobule tissues from AD patients revealed a significant increase in the level of S-glutathionylated GAPDH compared with the level in age-matched controls (144) (Fig. 4). Tau, a microtubule-associated protein mainly expressed in the CNS, promotes neurite extension and axonal growth. However, tau is considered to be the major component of the neurofibrillary tangles observed in the brain tissue of patients with AD (70). Electron microscopy analysis suggested that S-glutathionylated tau protein rapidly polymerized to form filaments (50).

The proapoptotic transcriptional factor p53 was also found to be hyperglutathionylated in AD patients, although the biological consequence of this is not clear yet. One explanation 


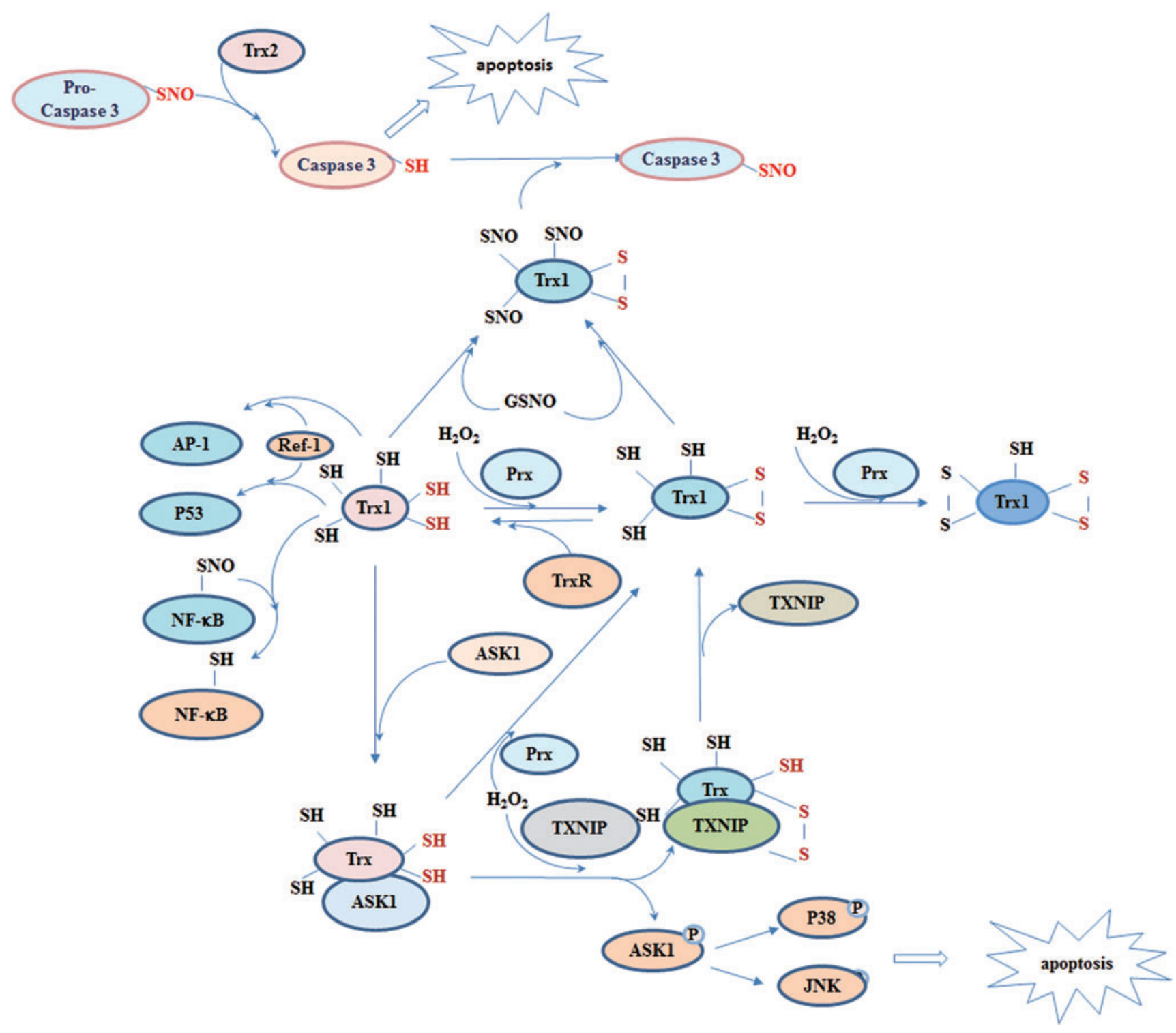

FIG. 5. Trx regulated cell death pathways. Trx is a redox regulator for several transcription factors involved in many cellular events in the central nervous system, for example, AP-1, NF- $\kappa \mathrm{B}$, and $\mathrm{p} 53$. Trx 1 can directly prevent cell death by binding ASK1. Not surprisingly, TXNIP, the endogenous inhibitor of Trx1, can promote ASK1-mediated apoptosis. Different redox statuses of Trx1 exert different effects on caspases. Reduced Trxs can denitrosylate and activate caspase 3, which executes apoptosis, while oxidized Trx 1 can be nitrosylated and subsequently transnitrosylate caspase 3 thereby curbs caspase 3-mediated apoptosis. ASK1, apoptosis-signaling kinase 1; TXNIP, thioredoxin-interacting protein. To see this illustration in color, the reader is referred to the web version of this article at www.liebertpub.com/ars

is that glutathionylation protects p53 from irreversible oxidation and degradation, therefore promoting neuronal cell death (49). Another speculation is that glutathionylation of p53 is an adaptive response to suppress apoptotic signaling under stress (203).

The mitochondrial $\mathrm{NADP}^{+}$-dependent isocitrate dehydrogenase (IDPm) catalyzes oxidative decarboxylation of isocitrate to $\alpha$-ketoglutarate and produces $\mathrm{NADPH}$, which supplies electrons for antioxidant systems. Glutathionylation of Cys 269 within the active site inhibits IDPm activity. In a 1methyl-4-phenyl-1,2,3,6-tetrahydropyridine (MPTP)-induced PD mouse model, an increased level of glutathionylated IDPm was observed in the brain of PD mice compared with the control group (102). One of the mechanisms of MPTP-induced
PD is mediated by MPTP inhibition of complex I; decreased complex I activity is often observed in PD with lowered ATP production and elevated ROS formation (195). Glutathionylation of complex I inhibited its activity and increased ROS production in mitochondria, which might play a detrimental role in the brain (190).

The findings discussed above indicate that abnormal protein S-glutathionylation acts as a signal for diverse cellular activities, including protein aggregation, protein degradation, apoptosis, and mitochondrial dysfunction, which are closely linked to neurodegeneration.

$S$-glutathionylation regulated by Grxs. The reverse reaction of glutathionylation is termed S-deglutathionylation. 
Although several proteins, including Trxs (73), PDI (155), and sulfiredoxin (63), have deglutathionylase activity under different conditions, Grxs are considered to be the major deglutathionylases due to their high affinity and selectivity for glutathionylated proteins (91).

Two mechanisms have been proposed for Grx-catalyzed deglutathionylation: (i) the dithiol mechanism requires both cysteines in the active site-initially, the N-terminal cysteine forms a disulfide with the target protein and releases GSH, and subsequently, the other active site cysteine resolves the disulfide and leaves deglutathionylated protein and a resulting disulfide at the active site of Grx that can be later reduced by GSH; (ii) the monothiol mechanism suggests that the $\mathrm{N}$ terminal cysteine first takes over the -SG group, becoming glutathionylated and reducing the target protein, and subsequently, the glutathionylated active site cysteine is reduced by GSH or forms a disulfide with the other active site cysteine (133) (Fig. 6). Although both mechanisms were reported by different studies, the monothiol mechanism is considered to be prevalent due to its universal recognition of glutathionylated targets (61).

Grxs have an important influence on the nervous system through their ability to catalyze deglutathionylation. For example, actin was reported to be constitutively glutathionylated in the human CNS (182). Studies have shown that Grx1catalyzed deglutathionylation of actin is crucial for its polymerization, which is a key event required for cellular dynamics, and protects neurons from accumulation of disarranged actin filaments (153). In an MPTP-induced PD model, upregulation of Grx restored complex I activity, which is most likely mediated via deglutathionylation of its catalytic cysteines (101). Studies also revealed that Grx2a, the human mitochondrial Grx, exhibited higher affinity for glutathionylated substrates and electron donors compared with Grx1, suggesting it has an important role in regulating mitochondrial redox homeostasis by deglutathionylation of target proteins, including complex I (19, 91). Glutathionylation of cysteine in the active site of $\operatorname{Prx} 2$ was also reported in Grx 1 knockout cells treated with $\mathrm{H}_{2} \mathrm{O}_{2}$, suggesting that Grx 1 has a protective role in guarding Prx 2 activity under oxidative stress (158). Mutation of the Parkinsonismassociated deglycase (PARK7/DJ-1) gene or loss of DJ-1 protein function is associated with autosomal recessive earlyonset PD. An in vivo study suggested that the DJ-1 protein level was regulated by Grx1-mediated deglutathionylation, which protected DJ-1 from proteasome degradation and exerted beneficial effects in PD (93). A recent study using a Caenorhabditis elegans PD model reported that global deficiency of GLRX-10, the homolog of mammalian Grx1, aggravated neurodegenerative symptoms in worms (94).

The results described above indicate that protein $\mathrm{S}$ glutathionylation is an important signal for neuron cell death, for example, via the effects on abnormal protein polymerization and protein degradation. Grxs, including Grx1 and Grx2, are important mediators of protection against oxidative stress in the CNS by reversal of S-glutathionylation.

S-sulfhydration. Similar to NO, hydrogen sulfide $\left(\mathrm{H}_{2} \mathrm{~S}\right)$ also targets reactive protein cysteines and forms persulfide bonds (-SSH). This cysteine-based PTM is termed Ssulfhydration, which has recently drawn attention for its biological functions. Compared with S-nitrosylation, which only occurs in a small fraction of proteins, sulfhydration is a more abundant PTM that has been reported to modify 10$25 \%$ of the total proteins in liver lysates, including actin, tubulin, and GAPDH (140). S-nitrosylation usually inhibits the activity of proteins, whereas sulfhydration typically enhances the reactivity of modified cysteines.

S-sulfhydration in the neuronal system. S-sulfhydration regulates various biological events in the CNS and some of the modifications are protective. For example, sulfhydration of parkin enhances its E3 ligase activity, and depleted parkin sulfhydration was detected in brain samples from PD patients, suggesting a beneficial effect on the clearing of misfolded proteins in the brain (202). $\mathrm{H}_{2} \mathrm{~S}$ also boosted $\mathrm{GSH}$ production by enhancing the activity of the rate-limiting enzyme, $\gamma$-glutamyl cysteine synthetase ( $\gamma$-GCS). Although the mechanism is not clear yet, it is possible that $\gamma$-GCS activity is enhanced through sulfhydration (103). Sulfhydration of Keap1 led to activation of Nrf2 that increases cellular antioxidant capacity and protects against senescence (215). In another oxidative stress-induced neuronal senescence model, sulfhydration of p66Shc, a protein that controls mitochondrial ROS production, hampered its translocation into the mitochondria and lowered ROS production (212). Sulfhydration of the p65 subunit of NF- $\kappa \mathrm{B}$ was shown to promote its binding to coactivator ribosomal protein S3 (RPS3) and facilitated its antiapoptotic effects (176).

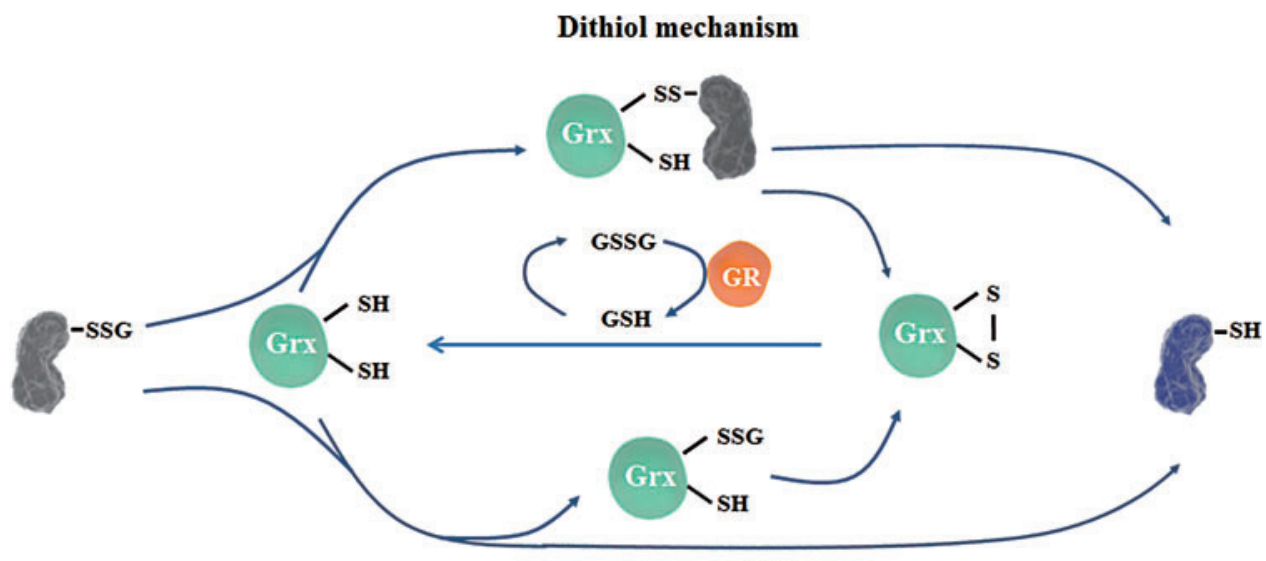

Monothiol mechanism
FIG. 6. Two proposed mechanisms for Grx catalyzed degulathionylation. The dithiol mechanism (upper part) requires both active site cysteines. During reaction, Nterminal active site cysteine forms disulfide with targeted proteins. The monothiol mechanism (lower part) needs only the N-terminal active site cysteine, which takes over the GSH mixed disulfide from targeted proteins. To see this illustration in color, the reader is referred to the web version of this article at www.liebertpub .com/ars 
Excessive sulfhydration is harmful to the nervous system. Chronic inflammation is one of the hallmarks of neurodegenerative diseases. Inflammatory cytokines can cause sulfhydration of GAPDH and enhance its binding to Siah1 (Fig. 4). This binding promotes Siah1 activity, which subsequently leads to degradation of postsynaptic density 95 (PSD95), an important protein involved in neuron maturation and synaptic plasticity. Exaggerated loss of PSD95 is seen in several neuronal diseases, including dementia and depression (135). As the gene that encodes cystathionine $\beta$-synthase (CBS), the enzyme that produces $\mathrm{H}_{2} \mathrm{~S}$ in cells, is located on chromosome 21, patients with Down's syndrome (DS) or trisomy 21 have much higher $\mathrm{H}_{2} \mathrm{~S}$ production, which may cause hypersulfhydration. This hypersulfhydration has been hypothesized to be one of the contributors to the effects in the CNS during early-onset AD in adults and impaired brain growth in children (89). However, further studies and more conclusive evidence are needed to consolidate the link between hypersulfhydration and DS-related symptoms.

Regulation of S-desulfhydration. Several studies have reported that the Trx system catalyzes desulfhydration, the reverse reaction of sulfhydration, under different conditions (105, 134). Recent studies using different methods have suggested that the Trx system globally regulates cellular desulfhydration $(96,205)$. The Grx system and Trx-related protein of $14-\mathrm{kDa}$ (TRP14) are also able to reduce protein sulfhydration (52). Our overall understanding of desulfhydration remains incomplete and more effort is required to elucidate the whole picture.

\section{Redox regulation of receptor signaling}

Activation of protein tyrosine kinases (PTKs) to phosphorylate target proteins is a common mechanism to transduce ligand-receptor-based signals, which are important for growth factor-mediated neural development. Therefore, protein tyrosine phosphatases (PTPs), which negatively regulate the activity of PTKs and downstream cascades, are important to maintain the balance of total protein phosphorylation.

Although members in the PTP superfamily share limited sequence similarity, the presence of a -CXXXXXR- (X can be any amino acid) motif in the active site is a common catalytic hallmark for PTPs (194). Due its low pKa value (4-6.5), the cysteine in the active site of PTPs exists as a thiolate $\left(-S^{-}\right)$at physiological $\mathrm{pH}$ and it is sensitive to ROS or RNS modification in vivo (159). In particular, upon growth factor stimulation, ROS transiently and locally produced by NOX are required to activate PTKs and downstream cascades (187). During the last two decades, redox regulation of PTPs in signal transduction has received much attention due to its implication in various physiological and pathological settings in the CNS. Details have been discussed in recent reviews $(81,112)$.

Inactivation of PTPs by other oxidants, such as $\mathrm{H}_{2} \mathrm{O}_{2}(48)$, oxidized GSH (GSSG) (14), lipid peroxide (42), NO (13), and $\mathrm{H}_{2} \mathrm{~S}$ (105), results in reversible cysteine modifications, such as sulfenic acid, glutathionylation, disulfide bonds, nitrosylation, or sulfhydration. The oxidized PTPs can be reduced and restored by the Trx and GSH systems (113). Interestingly, the Trx system was reported to exhibit certain specificity toward different PTPs. A recent study showed that both Trx1 and Trp14 coupled with TrxR and NADPH can reactivate oxidized
PTP1B, but not SHP2, another member of the PTP family (45). Grx was reported to reduce glutathionylated PTP1B and restore its phosphatase activity (14).

Prx (38) and GPx (42) also contribute to receptor signaling due to their high efficiency for removing peroxides and protection of PTPs from oxidation. Prx can protect PTEN from oxidation by a direct protein-protein interaction (33). Interestingly, under certain conditions, Prx acts as an oxidase of PTPs, in contrast to its typical well-characterized role as an $\mathrm{H}_{2} \mathrm{O}_{2}$ scavenger. During $\mathrm{H}_{2} \mathrm{O}_{2}$ burst, the cysteine at the active site of Prx is initially oxidized into sulfenic acid or intra-/ intermolecular disulfide, then the oxidized Prx may selectively transfer the equivalent oxidation to target proteins via specific protein-protein interactions (74). However, more evidence is needed to understand this process in mammalian cells. It was also reported that growth factor stimulation inactivated Prx via phosphorylation and that dephosphorylation by PTPs may restore Prx activity (208).

\section{Trx and GSH Systems in CNS Disorders}

Several human CNS disorders, such as ischemia/reperfusion (I/R) damage and neurodegenerative diseases, are characterized by dysregulated apoptosis and accumulation of damaged proteins, DNA, and membranes. Dysfunction of many cellular processes, including protein degradation, ROS removal, mitochondrial function, and neuroinflammatory responses, contributes to pathological processes (115). Failure to respond correctly to oxidative stress, generation of ROS, and protein aggregation may be involved in pathogenesis (90). Since GSH and Trx are the major players in redox signaling, it is not surprising that changes in these two systems have been found in the aforementioned diseases $(2,10,120)$.

Aging is a major risk factor for neurodegenerative disorders and is associated with higher production of ROS and the progressive loss of certain neuronal populations (129). Downregulated expression of Trx and GSH system proteins resulting in attenuated antioxidant activity has been observed during aging (171), and overexpression of components of these two systems was shown to rescue the aging-related phenotype in several animal models $(67,137)$. The Trx 1 and Grx 1 levels in cerebrospinal fluid are correlated with the expression of the established AD markers, tau and phospho-tau, in AD patients (10).

\section{Regulation of redox-sensitive apoptosis induced by ER stress}

Accumulation of misfolded proteins caused by ER stress is a hallmark of neurodegenerative diseases. ER is an important organelle for protein quality control and ensures that proteins are synthesized, folded, and post-translationally modified correctly. Disturbance of ER function leads to ER stress, which may sequentially trigger undesired apoptosis (213).

Trxs are critical mediators of ER stress-induced apoptotic signaling. Trx1 has been found to be a physiological inhibitor of apoptosis-signaling kinase 1 (ASK1) via a direct proteinprotein interaction. ASK1 is a mitogen-activated protein kinase kinase kinase (MAP3K) and activates MAP2K-JNK/ MAPK-p38 signaling cascades, which are essential for ER stress-induced apoptosis (146). Trx1 inhibits ASK1 kinase activity via the formation of a disulfide between its active site Cys32 or Cys35 and Cys250 in the N-terminal portion of 
ASK1. When cytosolic Trx1 is oxidized in response to proinflammatory stimuli, ROS, and cellular stress, ASK1 is released from Trx1-ASK1 complexes and subsequent ASK1dependent apoptosis is activated (Fig. 6). Trx2 associates with mitochondrial ASK1 via binding with the ASK1 Cys30 and activates a JNK-independent apoptosis pathway (222).

The activity of Trx is also regulated by Trx-interacting protein (TXNIP), its endogenous inhibitor (147), which is also induced during ER stress (149). The interaction between Trx and TXNIP involves disulfide formation between Cys 32 in Trx and Cys247 in TXNIP, which may be regulated by an internal disulfide switching mechanism between Cys63Cys247 and Cys63-Cys190 in TXNIP (87).

\section{Regulation of redox-sensitive apoptosis in $I / R$}

ROS production is involved in ischemic brain damage, thus overexpression of antioxidant enzymes, such as Trxs and Prx2, attenuates cerebral infarction following ischemia and I/R. Prx 2 protects brain tissue from I/R-induced injury by suppressing the ASK1/JNK-mediated mitochondrial signaling pathway (68). Prx2 also attenuates the poly(ADP-ribose) polymerase 1 (PARP1) and p53-dependent cell death pathway (110).

The NMDA receptor is a critical mediator during ischemic brain damage. The TXNIP pathway has been shown to be involved in neuroprotection mediated by the synaptic NMDA receptor in rat neurons. Synaptic activity blocks TXNIP expression and activates the expression of sulfiredoxin and sestrin 2, thus enhancing reduction of Prx by the Trx system and facilitating intrinsic antioxidant defenses in neurons (150). Although the Trx system has a protective role in cerebral I/R, the mitochondrial Trx system has been indicated to be involved in caspase 3-mediated neuronal apoptosis in rat hippocampus (186). Cerebral I/R can activate glutamate receptor 6 (GluR6), which upregulates the expression of FasL, and thus enhances the expression of TrxR2 and Trx2. The mitochondrial Trx2 system then denitrosylates and activates procaspase 3 (186) (Fig. 5).

\section{GSH in health and diseases of human CNS}

GSH is the most abundant thiol-containing molecule and one of the most important antioxidants involved in neuroprotection (8). The GSH level in the brain is $\sim 2-3 \mathrm{mM}$ (43); it is highest in the cortex, followed by the cerebellum, hippocampus, and striatum, and is lowest in the substantia nigra (97).

GSH reacts nonenzymatically with oxidants to inhibit oxidative stress in the cell, including superoxides, NO, hydroxyl radicals, and peroxynitrite. In addition, GSH reacts enzymatically with GPx and GSH-S-transferase (GST) against neurodegeneration (9). In neurons, GR is sufficiently active to allow the rapid reduction of accumulated GSSG (55). Under oxidative stress, GR maintains the equilibrium of the GSH/GSSG redox state in the cell. Most importantly, GSH depletion induced by oxidative stress can exacerbate oxidative injury in the brain (126).

An age-related decline in GSH level has been observed in humans, and the GSH concentration in the cerebral spinal fluid decreases with age. Such findings suggest that agingassociated decreases in GSH may underlie changes to antioxidant capacity, which occur during aging and during the onset of various aging-related diseases (193). Previous works have suggested that GSH depletion is involved in neurodegeneration (175). Indeed, the GSH levels are decreased in the brain in some neurodegenerative diseases, but it remains unclear whether the decreased GSH level is a cause or an outcome of neurodegeneration (163). In PD, although there is a 30-40\% decrease in GSH concentrations, no corresponding increase in the level of GSSG has been detected, thus the reason for GSH depletion is not clear (178). In AD, the total GSH level in brain is not affected, whereas GPx and GR were found to be either elevated or unchanged in different brain regions (157). In clinically isolated syndrome and relapsingremitting multiple sclerosis, there is evidence that GSH content and GPx activity are decreased, and the former might serve as a marker closely correlated with the neurological scoring of acute CNS inflammation (117). The low concentration of GSH during inflammation is likely to be a consequence of accelerated turnover linked to elevated oxidative stress. In a beta-Noxalyl amino-L-alanine (L-BOAA)-induced mouse model of neurolathyrism (a motor neuron disease involving the pyramidal system), GSH loss and inhibition of mitochondrial complex I were observed in the lumbosacral cord of male mice (51). Other CNS toxicants such as ethanol also cause a decrease in GSH concentration, particularly in the cerebellum, striatum, and cortex, which may be associated with an increase in the concentration of acetaldehyde, which is normally removed from cells by GSH (11).

\section{Modification of Trx and GSH Systems by Small Molecules in the CNS}

Since the Trx and GSH systems are so important in the CNS, many small molecules can exert their effects in the CNS via modification of the two thiol-based signaling pathways. Several examples are discussed below.

\section{Mercury}

Exposure to mercury $(\mathrm{Hg})$, whether it is in the form of methylmercury $(\mathrm{MeHg})$ in ingested fish, mercury vapor $\left(\mathrm{Hg}^{0}\right)$ released from dental amalgams, or ethylmercury $(\mathrm{EtHg})$ derived from thimerosal-containing vaccines, results in its accumulation in the CNS, which eventually leads to neurotoxicity. The neurotoxic effects are particularly serious if exposure to $\mathrm{Hg}$ takes place during fetal development, or in early infancy, due to the immaturity of the CNS and BBB (40).

Systemic distribution of $\mathrm{MeHg}$ and its accumulation in the CNS are facilitated by binding to - $\mathrm{SH}$ groups in cysteine due to the molecular similarity between the MeHg-Cys complex and the amino acid methionine, which enables $\mathrm{MeHg}-\mathrm{Cys}$ transport across the $\mathrm{BBB}$ and into the brain via neutral amino acid transporters (39). On the other hand, $\mathrm{Hg}^{\mathrm{O}}$ has no charge and can freely diffuse across membranes and reach the CNS. Both the organic species of $\mathrm{Hg}$ and $\mathrm{Hg}$ vapor are converted to the highly reactive $\mathrm{Hg}^{2+}$. In fact, $\mathrm{Hg}^{2+}$ is the most abundant $\mathrm{Hg}$ species found in the brain following chronic exposure to $\mathrm{MeHg}, \mathrm{EtHg}$, or $\mathrm{Hg}^{0}(32,201)$.

One of the known mechanisms by which $\mathrm{Hg}$ exerts neurotoxicity is through the disruption of glutamate (Glu) transport, either by increasing its release from the presynaptic terminal or by inhibiting its reuptake from the synaptic cleft by astrocytes. Impairment of glutamate uptake is associated with increased ROS production and subsequent oxidative stress (60). The Hg electrophilic nature underlies its oxidative 


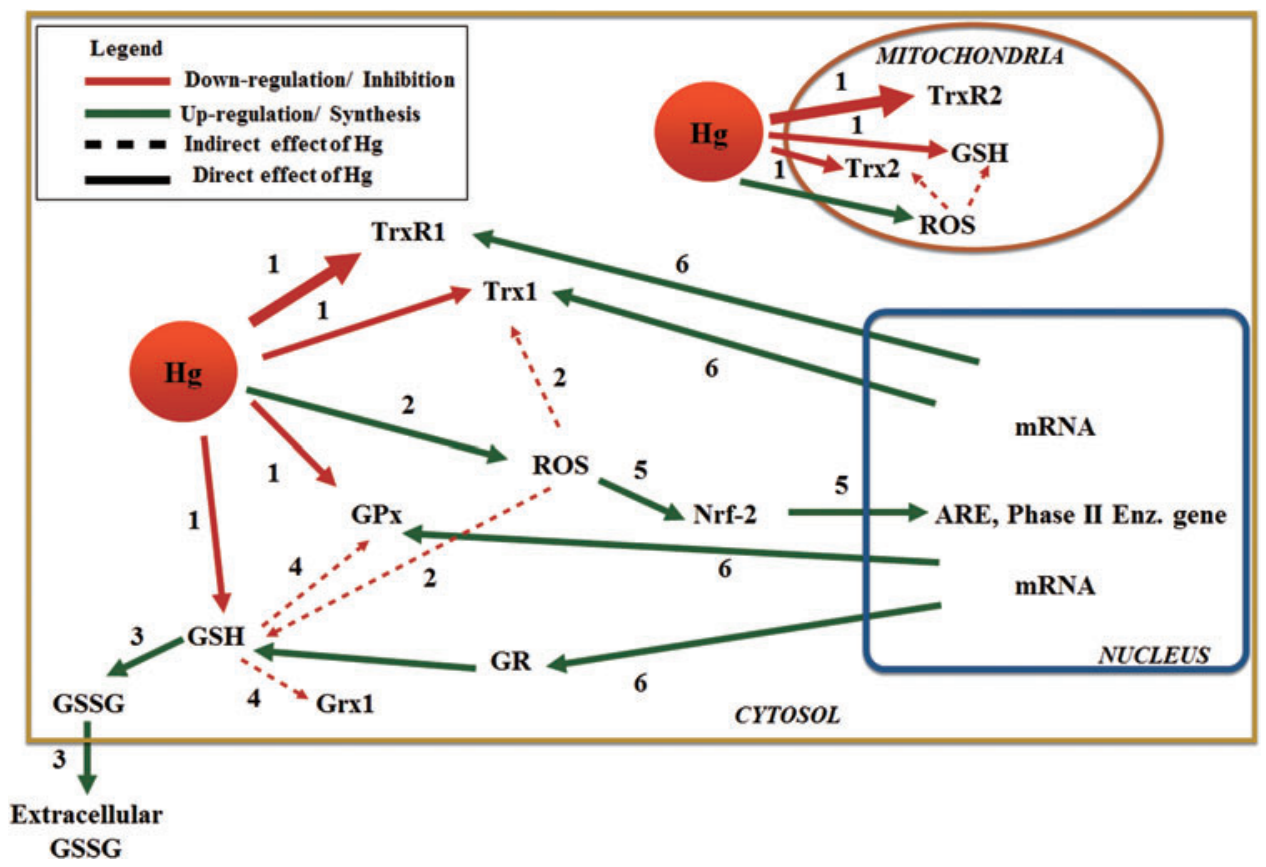

FIG. 7. X-Interaction between Mercury Compounds and Trx and GSH Systems. Mercury compounds target directly thiols and selenols in the individual components of Trx and GSH systems (step 1) in the cytosol and mitochondria, causing decreased activity. TrxR1 and 2 are major targets. Additionally, generation of ROS (step 2) aggravates the oxidation of sensitive targets (e.g., GSH and Trx1). Oxidation of GSH (step 3) further decreases activity of GSH-dependent enzymes, even when they are not direct targets of $\mathrm{Hg}$ (e.g., Grx1; step 4), and increases GSSG that is excreted by the cell. ROS production releases Nrf2, which is translocated to the nucleus (step 5), and induces Phase II enzyme synthesis (e.g., GR) in an attempt to counteract oxidative effects (step 6). Pathways and cellular structures are oversimplified for a matter of clarity. $\mathrm{Hg}$, mercury; Nrf2, nuclear factor E2-related factor 2. To see this illustration in color, the reader is referred to the web version of this article at www.liebertpub.com/ars

effects and its high binding affinity for thiols and selenols (35, 169). As a result, both the GSH and Trx systems are targets for mercurial compounds (Fig. 7).

Depletion of GSH has been shown to occur after exposure to $\mathrm{Hg}$ compounds in vitro and in vivo using experimental animals $(47,204)$. In primary cultures of neurons and astrocytes, GSH was decreased by $30-50 \%$ following a 30 -min treatment with $5 \mu M \mathrm{MeHg}$ (98). This abrupt decrease in GSH levels cannot be explained on the basis of a 1:1 complex formation. Therefore, it is likely that upon exposure to $\mathrm{Hg}$, ROS generation plays an important role in GSH oxidation with the subsequent formation and excretion of GSSG. Additionally, decreased synthesis of GSH, due to impaired uptake of its precursor Glu, leads to higher ROS generation (47) (Fig. 7). Concomitantly, in the study by Kaur et al., pretreatment with diethylmaleate depleted cellular GSH and further aggravated $\mathrm{MeHg}$ toxicity, whereas pretreatment with $\mathrm{N}$-acetylcysteine increased the intracellular GSH level and offered additional protection against toxicity (98). Most interestingly, in vivo data suggest that GR activity in the brain is increased by exposure to $\mathrm{MeHg}$, which may function as a compensatory response following GSH oxidation (27).

The pivotal role of GSH in modulating $\mathrm{Hg}$ toxicity cannot be separated from the fact that it is an important cofactor for enzymes involved in antioxidant defense, such as GPxs and Grxs. GPx1, an important scavenger of $\mathrm{H}_{2} \mathrm{O}_{2}$, is affected by exposure to mercurials, in particular $\mathrm{MeHg}$. Likewise, membranelocated GPx4 presented decreased activity and expression in the cortex and cerebellum of mice exposed to $\mathrm{MeHg}$ (220). Besides dependence on GSH as an electron donor, GPx activity relies on the reducing ability of Sec residue in the active site. This $\mathrm{Sec}$ is prone to direct interaction with $\mathrm{MeHg}$ (28), but not $\mathrm{Hg}^{2+}$, as shown in vitro by Bulato et al. (31).

Data on the interaction between $\mathrm{Hg}$ and Grxs are scarce. We have previously reported that both $\mathrm{MeHg}$ and $\mathrm{Hg}^{2+}$ target the thiols in purified Grx1; however, in HeLa cells, inhibition of Grx activity is only achieved at very high concentrations. To the best of our knowledge, there are no reports concerning the interaction between $\mathrm{Hg}$ and Grx in CNS models or in experimental animals (34).

The Trx system has been proven to be particularly sensitive to $\mathrm{Hg}$. Trx $\mathrm{R}$ is a prime target for mercurials due to the high reactivity and location of the Sec residue at the open $\mathrm{C}$ terminal $(34,35)$. Several in vitro and in vivo studies have shown a significant drop in TrxR activity in the brain following exposure to different $\mathrm{Hg}$ compounds, which is both time and concentration dependent $(27,28,166,220)$. In liver cells, inhibition of cytosolic TrxR 1 by $\mathrm{Hg}^{2+}$ is counteracted by upregulation of TrxR1 synthesis via the Nrf2 pathway (29). This Nrf2 response is weaker during exposure to $\mathrm{MeHg}$, resulting in decreased expression of TrxR1. It has been shown that a fast $\mathrm{Nrf} 2$ response occurs upon $\mathrm{MeHg}$ exposure in microglia and neurons (145); however, the relationship between Nrf2 signaling and TrxR1 in the CNS has not been fully elucidated. Contrary to its cytosolic counterpart, TrxR2 is not regulated by $\operatorname{Nrf} 2$ (29) and thus it might be a very 
important early target in the development of $\mathrm{Hg}$ toxicity. In fact, TrxR2 and the overall mitochondrial Trx system, via Prx3, play a vital role in the detoxification of $\mathrm{H}_{2} \mathrm{O}_{2}$ in brain mitochondria, and TrxR2 inhibition increases the sensitivity of CNS cells to other environmental stressors such as paraquat (PQ) (118).

Trx 1 is also inhibited by mercurials in vitro with a $1: 2.5$ and 1:5 enzyme:inhibitor ratio for $\mathrm{Hg}^{2+}$ and $\mathrm{MeHg}$, respectively (34). In SH-SY5Y cells exposed to EtHg (166) and in the brain of experimental animals exposed to $\mathrm{MeHg}$ and $\mathrm{Hg}^{2+}$, Trx activity is inhibited in a dose-dependent manner similarly to the effect on TrxR, although the reduction in activity is less significant $(27,28)$.

\section{Paraquat}

PQ (1,1'-dimethyl-4-4'-bipyridinium dichloride) is a typical quaternary ammonium herbicide, which kills plants nonselectively by targeting the chloroplasts in green plant tissues. In plants, PQ mainly exerts its toxic effect by acting as a redox cycler, which can constantly consume NADPH and disturb the electron transfer photosystems (25). In humans, PQ is not easily absorbed from the skin or gut. Once absorbed, PQ mainly accumulates in lungs and causes pulmonary fibrosis. Acute PQ poisoning results in respiratory failure and death within a few days or weeks. Chronic exposure to PQ leads to elevated oxidative stress in the plasma, including increased lipid peroxidation, decreased antioxidant capacity (affecting the ferric-reducing ability of plasma), and decreased blood thiol content (164). Although it is still under debate whether PQ can pass through the BBB and exert its toxic effect directly in the brain $(15,16,30,177)$, many epidemiological and etiological studies have shown a clear association between low-dose exposure (absence of acute toxicity) to PQ and neurodegenerative diseases, especially PD. Mechanistic studies also demonstrated that PQ can induce apoptotic cell death in several types of neu- ronal cells in association with PD, including in cerebellar granule cells and other dopaminergic neurons (71).

In mammalian cells, the mechanism of PQ-induced toxicity is very similar to the mechanism in plant cells. PQ ions $\left(\mathrm{PQ}^{2+}\right)$ are reduced to the free radical form of $\mathrm{PQ}\left(\mathrm{PQ}^{\bullet+}\right)$ by $\mathrm{NADPH} . \mathrm{PQ}^{\bullet+}$ can spontaneously react with oxygen, resulting in the formation of superoxide anion $\left(\mathrm{O}_{2}{ }^{-}\right)$, which then leads to the generation of other types of ROS, including $\mathrm{H}_{2} \mathrm{O}_{2}$ and hydroxyl radicals (25). The overproduction of ROS then causes damage to proteins, lipid membranes, and DNA (Fig. 8). Furthermore, PQ constantly consumes NADPH and disrupts essential NADPH-dependent biochemical processes (167) (Fig. 8). Besides acting as a redox cycler, the role of mitochondria in PQ neurotoxicity has been addressed. ROS generation following PQ exposure is dependent on respiratory chain components, especially complex III (36).

Trx and Grx systems are not only very important for the defense against PQ toxicity but are also disrupted by PQ toxicity as both systems use NADPH as the ultimate electron donor. In SH-SY5Y and SK-N-MC human neuroblastoma cell lines, PQ was found to oxidize Trx1 and activate the ASK1/ $\mathrm{JNK} /$ caspase 3 cascade. PQ treatment also reduced the activity of TrxR and GPx $(188,198)$. Dopaminergic N27 cells were sensitized to PQ treatment by disruption of mitochondrial Trx2 and TrxR2 (118). Drosophila with Trx 2 loss of function were sensitized to PQ toxicity (197). In Drosophila cells, Prxs also had a cytoprotective effect following PQ treatment (162). The expression of certain Trx and Grx system proteins is regulated by the transcription factor Nrf2. Although PQ treatment was found to decrease the protein level of Nrf2, it can also activate the Nrf2 pathway and increase the transcription of target genes $(167,216)$. TrxR appears to have a dual role in PQ toxicity. Several studies in different species have reported that TrxR has a protective role following PQ treatment $(118,142)$. However, in the presence of NADPH, TrxR was found to reduce $P Q$ and generate ROS that may contribute to its

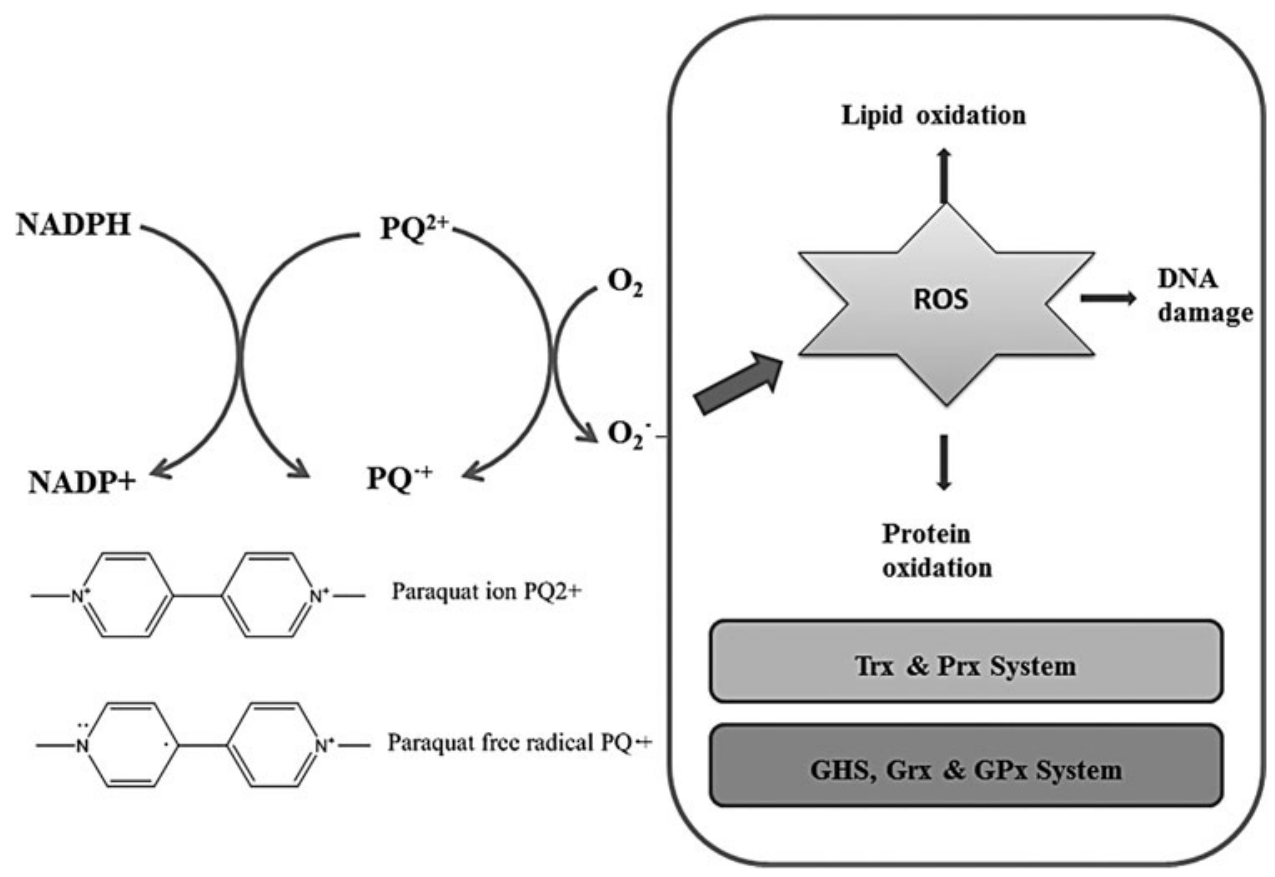

FIG. 8. The toxicity mechanism of $P Q$ in mammalian cells. PQ undergoes redox cycling in cells to generate large amount of ROS, which cause lipid peroxidation, DNA damage, and protein oxidation and heavily disturb Trx and GSH systems. PQ, paraquat. 
toxicity $(72,189)$. Several known antioxidants or proteins with antioxidant properties, including vitamin $\mathrm{C}$, vitamin $\mathrm{E}$, Se, $N$-acetylcysteine, and coenzyme Q10 (CoQ10), were found to have protective roles against PQ treatment $(12,71$, $132,188,198,219)$. These findings also suggest the importance of antioxidant enzymes for protection against PQ toxicity.

\section{Coenzyme $Q$}

CoQ10 (ubiquinone) is an electron carrier lipid of the mitochondrial respiratory chain and an endogenously synthesized antioxidant. CoQ10 can accept electrons from complex I and complex II and transfer them to complex III, which is considered to be the rate-limiting step in ATP production (130). CoQ10 is able to protect lipids from peroxidation in cell/ organelle membranes and in the circulation (168). As well as effects on lipid membranes, in vivo administration of CoQ10 can also protect membrane proteins (64) and DNA (192) from overoxidation. CoQ10 is also able to regenerate other antioxidant molecules, such as vitamin E (66). Additionally, oral administration of CoQ10 has been proven to be safe even at very high concentrations (3600 mg/day) (88).

The two major functions of CoQ10, oxidation and regeneration, both depend on changes in its redox state. In the mitochondrial matrix, CoQ10 is regenerated by the respiratory chain enzymes and the majority of CoQ10 in mitochondria is in its reduced form (1). In the other cellular compartments and plasma, several enzymes with reductase activity can regenerate CoQ10, including lipoamide dehydrogenase, TrxR, and GR. Compared with lipoamide dehydrogenase, full-length TrxR (in the presence of selenocysteine) is more effective, whereas the truncated form of TrxR does not have the ability to regenerate CoQ10 (211). This may also explain why several studies reported that the combined administration of Se and CoQ10 yields better cardiovascular protective effects than administration of CoQ10 only $(3,4)$.

It has been well established that mitochondrial dysfunction is associated with neurodegenerative diseases. In neuronal cells, pretreatment with CoQ10 was found to reduce ROS generation in mitochondria and protect neuronal cells from cell death induced by neurotoxins such as kainic acid (181). A decrease of CoQ10, or the reduced form of CoQ10, in SHSY5Y neuroblastoma cells resulted in increased oxidative stress (58). In rats, oral administration of CoQ10 can significantly increase the CoQ10 level in plasma, cells, and mitochondria and decrease oxidative damage to proteins (107). Several trials in humans and in rats have validated the beneficial role of CoQ10 in neurodegenerative diseases, such as PD and motor dysfunction disorders $(18,174)$.

\section{Selenium}

Se is an essential micronutrient with a narrow range of optimal concentrations. Disease can be caused by both Se insufficiency (e.g., Keshan disease) and an excessive Se intake (e.g., selenosis) (165). Upon entering cells, Se-containing compounds, organic or inorganic, are reduced to selenide $\left(\mathrm{Se}^{2-}\right)$ and then integrated in proteins in the form of selenocysteine by a fairly complex synthesis mechanism [reviewed in detailed by Papp et al. (151)]. At least 25 genes that encode selenoproteins have been identified in mammals, including genes encoding TrxR isoforms 1, 2, and 3 (TGR) and GPx isoforms 1, 2, 3, 4, and 6(151). At physiological $\mathrm{pH}$, the selenol $(-\mathrm{SeH})$ in the selenocysteine residue is in the form of selenolate $\left(-\mathrm{Se}^{-}\right)$, providing selenoenzymes with high reactivity and sensitivity to electrophilic agents (as previously discussed for $\mathrm{Hg}$ ) (35).

The brain is a prioritized organ for Se distribution, meaning that during periods of insufficient intake, the Se stored in visceral organs (e.g., liver) is redistributed to the brain (20). In agreement, TrxR activity was unchanged in the brain of rats fed an Se-deficient diet, whereas activity was reduced in the kidney and liver (82). In fish, supplementation of water with sodium selenite did not change TrxR activity in the brain, contrary to what was observed in the liver (28). However, SHSY5Y cells treated with $2.5 \mu M$ sodium selenite had a $40 \%$ increase in TrxR activity (166), indicating that Nrf2-mediated gene transcription was induced, as previously observed in the liver (29). The selenite amount used in these experiments is considerably higher than the reported $100 \mathrm{n} M$ necessary to optimize TrxR1 synthesis physiologically (156), and thus, it is expected that redox cycling and additional ROS formation will occur. However, it should be noted that the aforementioned experiments were performed with the aim of using Se as an antagonist to the toxicity of $\mathrm{Hg}$ compounds and to effectively recover the TrxR activity following inhibition by mercurials $\left(\mathrm{Hg}^{2+} ; \mathrm{MeHg}\right.$; EtHg), thus Se needs to be in a molar excess relative to the inhibitors $(29,35,166)$. In fact, selenite treatment is able to remove $\mathrm{Hg}^{2+}$ from the active site of TrxR1 and fully restore TrxR1 activity in vitro (35). The protective effect of selenite following $\mathrm{Hg}$-induced inhibition of TrxR1 has also been observed in SH-SY5Y cells (166).

Generally, GPx1 activity in the brain is not enhanced to the same extent as is TrxR1 upon Se supplementation, indicating its low ranking in the selenoprotein hierarchy (139). Nevertheless, GPx4 is essential for neuronal development and survival and has been reported to be highly expressed in $90 \%$ of the mouse brain (223). The use of the small organoselenium compound Ebselen, a mimetic of GPx activity, has been reported to offer antioxidant protection in the CNS (214). Interestingly, human subjects exposed to Ebselen exhibited reduced levels of brain GSH (128), which could be due to its GPx-like activity and GSH consumption. This contrasts with the upregulation of GSH observed in rat brain following selenite treatment $(108,183)$.

\section{Concluding Remarks}

Our knowledge of ROS has been renewed during last two decades. Instead of simply considering ROS as toxic molecules that are closely associated with various diseases, the physiological function of ROS as signaling messengers has been increasingly emphasized. Correspondingly, the Trx and GSH systems, as the two major antioxidant mechanisms, have also been highlighted for their pivotal roles as regulators of redox signaling. Redox signaling heavily relies on reversible modification of key thiols in proteins. Although the modifications are usually transient and ubiquitous, they surprisingly exhibit both tissue and target specificity. The CNS produces relatively high levels of ROS due to the large energy demand and, concurrently, is more susceptible to the damaging effects of ROS compared with other tissues. The Trx and GSH systems are the key factors required to maintain redox balance in the CNS. It is not surprising that both systems are 
dysfunctional in various neuronal disorders, especially in neurodegenerative diseases. Trxs can exert their antiapoptotic effect via binding ASK1 and thus protecting neurons from cell death. By closely evaluating several small compounds, we found that they all interact with the Trx and GSH systems and their beneficial or detrimental effects on CNS were further elucidated. However, further effort is needed to fully understand this complex system. New methods to measure ROS in a more physiologically relevant context should be developed, and biomarkers that can precisely predict and monitor ROS-related therapies are required. Furthermore, the misconception that ROS only act as damaging factors should be altered. It is likely that more redox signaling pathways regulated by the Trx and GSH systems, and the mechanisms involved, will be revealed. We believe that the field of redox signaling will attract more scientific efforts and be beneficial to patients suffering from various neuronal disorders.

\section{Acknowledgments}

The authors are thankful for the financial support of China Scholarship Council to X.R. and L.Z. C.C. and V.B. are supported by Fundação para a Ciência e Tecnologia, Portugal (www.fct.pt), through iMed.ULisboa's project UID/DTP/ $04138 / 2013$. V.B. is financed by a postdoctoral fellowship (SFRH/BPD/85219/2012) from FCT. J.W. is supported by B2016022, A16-301-14 (China). A.H. thanks the funding support from Swedish Cancer Society (961) and the Swedish Research Council Medicine (13X-3529). J.L. is grateful for the support of The hundred Talents Plan of Chongqing and Southwest University Gathering Talent Project (SWU116068).

\section{References}

1. Aberg F, Appelkvist EL, Dallner G, and Ernster L. Distribution and redox state of ubiquinones in rat and human tissues. Arch Biochem Biophys 295: 230-234, 1992.

2. Akterin S, Cowburn RF, Miranda-Vizuete A, Jimenez A, Bogdanovic N, WinbladB, and Cedazo-Minguez A. Involvement of glutaredoxin-1 and thioredoxin-1 in betaamyloid toxicity and Alzheimer's disease. Cell Death Differ 13: 1454-1465, 2006.

3. Alehagen U and Aaseth J. Selenium and coenzyme Q10 interrelationship in cardiovascular diseases - a clinician's point of view. J Trace Elem Med Biol 31: 157-162, 2015.

4. Alehagen U, Johansson P, Bjornstedt M, Rosen A, and Dahlstrom U. Cardiovascular mortality and N-terminalproBNP reduced after combined selenium and coenzyme Q10 supplementation: a 5-year prospective randomized double-blind placebo-controlled trial among elderly Swedish citizens. Int J Cardiol 167: 1860-1866, 2013.

5. Anand $P$ and Stamler JS. Enzymatic mechanisms regulating protein S-nitrosylation: implications in health and disease. J Mol Med (Berl) 90: 233-244, 2012.

6. Andreyev AY, Kushnareva YE, Murphy AN, and Starkov AA. Mitochondrial ROS metabolism: 10 years later. Biochemistry 80: 517-531, 2015.

7. Aon-Bertolino ML, Romero JI, Galeano P, Holubiec M, Badorrey MS, Saraceno GE, Hanschmann EM, Lillig CH, and Capani F. Thioredoxin and glutaredoxin system proteins-immunolocalization in the rat central nervous system. Biochim Biophys Acta 1810: 93-110, 2011.
8. Aoyama K and Nakaki T. Inhibition of GTRAP3-18 may increase neuroprotective glutathione (GSH) synthesis. Int J Mol Sci 13: 12017-12035, 2012.

9. Aoyama K, Watabe M, and Nakaki T. Regulation of neuronal glutathione synthesis. J Pharmacol Sci 108: 227-238, 2008.

10. Arodin L, Lamparter H, Karlsson H, Nennesmo I, Bjornstedt M, Schroder J, and Fernandes AP. Alteration of thioredoxin and glutaredoxin in the progression of Alzheimer's disease. J Alzheimers Dis 39: 787-797, 2014.

11. Augustyniak A, Michalak K, and Skrzydlewska E. [The action of oxidative stress induced by ethanol on the central nervous system (CNS)]. Postepy Hig Med Dosw (Online) 59: 464-471, 2005.

12. Awadalla EA. Efficacy of vitamin $\mathrm{C}$ against liver and kidney damage induced by paraquat toxicity. Exp Toxicol Pathol 64: 431-434, 2012.

13. Barrett DM, Black SM, Todor H, Schmidt-Ullrich RK, Dawson KS, and Mikkelsen RB. Inhibition of proteintyrosine phosphatases by mild oxidative stresses is dependent on S-nitrosylation. J Biol Chem 280: 14453-14461, 2005.

14. Barrett WC, DeGnore JP, Konig S, Fales HM, Keng YF, Zhang ZY, Yim MB, and Chock PB. Regulation of PTP1B via glutathionylation of the active site cysteine 215 . Biochemistry 38: 6699-6705, 1999.

15. Bartlett RM, Holden JE, Nickles RJ, Murali D, Barbee DL, Barnhart TE, Christian BT, and DeJesus OT. Paraquat is excluded by the blood brain barrier in rhesus macaque: an in vivo pet study. Brain Res 1259: 74-79, 2009.

16. Bartlett RM, Murali D, Nickles RJ, Barnhart TE, Holden JE, and DeJesus OT. Assessment of fetal brain uptake of paraquat in utero using in vivo PET/CT imaging. Toxicol Sci 122: 551-556, 2011.

17. Bazinet RP and Laye S. Polyunsaturated fatty acids and their metabolites in brain function and disease. Nat Rev Neurosci 15: 771-785, 2014.

18. Beal MF, Oakes D, Shoulson I, Henchcliffe C, Galpern WR, Haas R, Juncos JL, Nutt JG, Voss TS, Ravina B, Shults CM, Helles K, Snively V, Lew MF, Griebner B, Watts A, Gao S, Pourcher E, Bond L, Kompoliti K, Agarwal P, Sia C, Jog M, Cole L, Sultana M, Kurlan R, Richard I, Deeley C, Waters CH, Figueroa A, Arkun A, Brodsky M, Ondo WG, Hunter CB, Jimenez-Shahed J, Palao A, Miyasaki JM, Julie SO, Tetrud J, Reys L, Smith K, Singer C, Blenke A, Russell DS, Cotto C, Friedman JH, Lannon M, Zhang L, Drasby E, Kumar R, Subramanian T, Ford DS, Grimes DA, Cote D, Conway J, Siderowf AD, Evatt ML, Sommerfeld B, Lieberman AN, Okun MS, Rodriguez RL, Merritt S, Swartz CL, Martin WRW, King P, Stover N, Guthrie S, Watts RL, Ahmed A, Fernandez HH, Winters A, Mari Z, Dawson TM, Dunlop B, Feigin AS, Shannon B, Nirenberg MJ, Ogg M, Ellias SA, Thomas CA, Frei K, Bodis-Wollner I, Glazman S, Mayer T, Hauser RA, Pahwa R, Langhammer A, Ranawaya R, Derwent L, Sethi KD, Farrow B, Prakash R, Litvan I, Robinson A, Sahay A, Gartner M, Hinson VK, Markind S, Pelikan M, Perlmutter JS, Hartlein J, Molho E, Evans S, Adler CH, Duffy A, Lind M, Elmer L, Davis K, Spears J, Wilson S, Leehey MA, Hermanowicz N, Niswonger S, Shill HA, Obradov S, Rajput A, Cowper M, Lessig S, Song D, Fontaine D, Zadikoff C, Williams K, Blindauer KA, Bergholte J, Propsom CS, Stacy MA, Field J, Mihaila D, Chilton M, Uc EY, Sieren J, Simon DK, Kraics L, Silver A, 
Boyd JT, Hamill RW, Ingvoldstad C, Young J, Thomas K, Kostyk SK, Wojcieszek J, Pfeiffer RF, Panisset M, Beland M, Reich SG, Cines M, Zappala N, Rivest J, Zweig R, Lumina LP, Hilliard CL, Grill S, Kellermann M, Tuite P, Rolandelli S, Kang UJ, Young J, Rao J, Cook MM, Severt $\mathrm{L}$, and Boyar K. A randomized clinical trial of high-dosage coenzyme Q10 in early Parkinson disease no evidence of benefit. JAMA Neurol 71: 543-552, 2014.

19. Beer SM, Taylor ER, Brown SE, Dahm CC, Costa NJ, Runswick MJ, and Murphy MP. Glutaredoxin 2 catalyzes the reversible oxidation and glutathionylation of mitochondrial membrane thiol proteins-implications for mitochondrial redox regulation and antioxidant defense. J Biol Chem 279: 47939-47951, 2004.

20. Behne D, Pfeifer H, Rothlein D, and Kyriakopoulos A. Cellular and subcellular distribution of selenium and selenium-containing proteins in the rat. Trace Elem Man Anim 10: 29-34, 2000.

21. Benhar M, Forrester MT, Hess DT, and Stamler JS. Regulated protein denitrosylation by cytosolic and mitochondrial thioredoxins. Science 320: 1050-1054, 2008.

22. Benhar M, Forrester MT, and Stamler JS. Protein denitrosylation: enzymatic mechanisms and cellular functions. Nat Rev Mol Cell Biol 10: 721-732, 2009.

23. Benhar M, Thompson JW, Moseley MA, and Stamler JS. Identification of S-nitrosylated targets of thioredoxin using a quantitative proteomic approach. Biochemistry 49: 6963-6969, 2010.

24. Bilan DS and Belousov VV. HyPer family probes: state of the art. Antioxid Redox Signal 24: 731-751, 2016.

25. Blanco-Ayala T, Anderica-Romero AC, and PedrazaChaverri J. New insights into antioxidant strategies against paraquat toxicity. Free Radic Res 48: 623-640, 2014.

26. Bogdan C. Nitric oxide and the immune response. Nat Immunol 2: 907-916, 2001.

27. Branco V, Canario J, Holmgren A, and Carvalho C. Inhibition of the thioredoxin system in the brain and liver of zebra-seabreams exposed to waterborne methylmercury. Toxicol Appl Pharmacol 251: 95-103, 2011.

28. Branco V, Canario J, Lu J, Holmgren A, and Carvalho C. Mercury and selenium interaction in vivo: effects on thioredoxin reductase and glutathione peroxidase. Free Radic Biol Med 52: 781-793, 2012.

29. Branco V, Godinho-Santos A, Goncalves J, Lu J, Holmgren A, and Carvalho C. Mitochondrial thioredoxin reductase inhibition, selenium status, and Nrf-2 activation are determinant factors modulating the toxicity of mercury compounds. Free Radic Biol Med 73: 95-105, 2014.

30. Brooks AI, Chadwick CA, Gelbard HA, Cory-Slechta DA, and Federoff HJ. Paraquat elicited neurobehavioral syndrome caused by dopaminergic neuron loss. Brain Res 823: 1-10, 1999.

31. Bulato C, Bosello V, Ursini F, and Maiorino M. Effect of mercury on selenium utilization and selenoperoxidase activity in LNCaP cells. Free Radic Biol Med 42: 118123, 2007.

32. Burbacher TM, Shen DD, Liberato N, Grant KS, Cernichiari E, and Clarkson T. Comparison of blood and brain mercury levels in infant monkeys exposed to methylmercury or vaccines containing thimerosal. Environ Health Perspect 113: 1015-1021, 2005.
33. Cao J, Schulte J, Knight A, Leslie NR, Zagozdzon A, Bronson R, Manevich Y, Beeson C, and Neumann CA. Prdx1 inhibits tumorigenesis via regulating PTEN/AKT activity. EMBO J 28: 1505-1517, 2009.

34. Carvalho CML, Chew EH, Hashemy SI, Lu J, and Holmgren A. Inhibition of the human thioredoxin systema molecular mechanism of mercury toxicity. $J$ Biol Chem 283: 11913-11923, 2008.

35. Carvalho CML, Lu J, Zhang X, Arner ESJ, and Holmgren A. Effects of selenite and chelating agents on mammalian thioredoxin reductase inhibited by mercury: implications for treatment of mercury poisoning. FASEB $J$ 25: 370381, 2011.

36. Castello PR, Drechsel DA, and Patel M. Mitochondria are a major source of paraquat-induced reactive oxygen species production in the brain. J Biol Chem 282: 1418614193, 2007.

37. Cho DH, Nakamura T, Fang J, Cieplak P, Godzik A, Gu Z, and Lipton SA. S-nitrosylation of Drp1 mediates betaamyloid-related mitochondrial fission and neuronal injury. Science 324: 102-105, 2009.

38. Choi MH, Lee IK, Kim GW, Kim BU, Han YH, Yu DY, Park HS, Kim KY, Lee JS, Choi C, Bae YS, Lee BI, Rhee SG, and Kang SW. Regulation of PDGF signalling and vascular remodelling by peroxiredoxin II. Nature 435: 347-353, 2005.

39. Clarkson TW and Magos L. The toxicology of mercury and its chemical compounds. Crit Rev Toxicol 36: 609$662,2006$.

40. Clarkson TW, Magos L, and Myers GJ. Human exposure to mercury: the three modern dilemmas. J Trace Elem Exp Med 16: 321-343, 2003.

41. Clementi E, Brown GC, Feelisch M, and Moncada S. Persistent inhibition of cell respiration by nitric oxide: crucial role of S-nitrosylation of mitochondrial complex I and protective action of glutathione. Proc Natl Acad Sci U $S$ A 95: 7631-7636, 1998.

42. Conrad M, Sandin A, Forster H, Seiler A, Frijhoff J, Dagnell M, Bornkamm GW, Radmark O, van Huijsduijnen RH, Aspenstrom P, Bohmer F, and Ostman A. 12/15lipoxygenase-derived lipid peroxides control receptor tyrosine kinase signaling through oxidation of protein tyrosine phosphatases. Proc Natl Acad Sci U S A 107: 15774-15779, 2010.

43. Cooper AJ and Kristal BS. Multiple roles of glutathione in the central nervous system. Biol Chem 378: 793-802, 1997.

44. Cox AG, Winterbourn CC, and Hampton MB. Mitochondrial peroxiredoxin involvement in antioxidant defence and redox signalling. Biochem J 425: 313-325, 2010.

45. Dagnell M, Frijhoff J, Pader I, Augsten M, Boivin B, Xu J, Mandal PK, Tonks NK, Hellberg C, Conrad M, Arner ES, and Ostman A. Selective activation of oxidized PTP1B by the thioredoxin system modulates PDGF-beta receptor tyrosine kinase signaling. Proc Natl Acad Sci U S A 110: 13398-13403, 2013.

46. DelaTorre A, Schroeder RA, and Kuo PC. Alteration of NF-kappa B p50 DNA binding kinetics by S-nitrosylation. Biochem Biophys Res Commun 238: 703-706, 1997.

47. Deng Y, Xu ZF, Xu B, Liu W, Wei YG, Li YH, Feng S, and Yang TY. Exploring cross-talk between oxidative damage and excitotoxicity and the effects of riluzole in 
the rat cortex after exposure to methylmercury. Neurotox Res 26: 40-51, 2014.

48. Denu JM and Tanner KG. Specific and reversible inactivation of protein tyrosine phosphatases by hydrogen peroxide: evidence for a sulfenic acid intermediate and implications for redox regulation. Biochemistry 37: 56335642, 1998.

49. Di Domenico F, Cenini G, Sultana R, Perluigi M, Uberti D, Memo M, and Butterfield DA. Glutathionylation of the pro-apoptotic protein p53 in Alzheimer's disease brain: implications for AD pathogenesis (vol 34, pg 727, 2009). Neurochem Res 34: 1354-1354, 2009.

50. Dinoto L, Deture MA, and Purich DL. Structural insights into Alzheimer filament assembly pathways based on sitedirected mutagenesis and S-glutathionylation of three-repeat neuronal Tau protein. Microsc Res Tech 67: 156-163, 2005.

51. Diwakar L, Kenchappa RS, Annepu J, and Ravindranath V. Downregulation of glutaredoxin but not glutathione loss leads to mitochondrial dysfunction in female mice CNS: implications in excitotoxicity. Neurochem Int 51: 37-46, 2007.

52. Doka E, Pader I, Biro A, Johansson K, Cheng Q, Ballago K, Prigge JR, Pastor-Flores D, Dick TP, Schmidt EE, Arner ES, and Nagy P. A novel persulfide detection method reveals protein persulfide- and polysulfide-reducing functions of thioredoxin and glutathione systems. Sci Adv 2: e1500968, 2016.

53. Drechsel DA and Patel M. Respiration-dependent $\mathrm{H} 2 \mathrm{O} 2$ removal in brain mitochondria via the thioredoxin/peroxiredoxin system. J Biol Chem 285: 27850-27858, 2010.

54. Dringen R. Metabolism and functions of glutathione in brain. Prog Neurobiol 62: 649-671, 2000.

55. Dringen R, Kussmaul L, Gutterer JM, Hirrlinger J, and Hamprecht B. The glutathione system of peroxide detoxification is less efficient in neurons than in astroglial cells. J Neurochem 72: 2523-2530, 1999.

56. Du Y, Zhang H, Lu J, and Holmgren A. Glutathione and glutaredoxin act as a backup of human thioredoxin reductase 1 to reduce thioredoxin 1 preventing cell death by aurothioglucose. J Biol Chem 287: 38210-38219, 2012.

57. Du Y, Zhang $\mathrm{H}$, Zhang $\mathrm{X}$, Lu J, and Holmgren A. Thioredoxin 1 is inactivated due to oxidation induced by peroxiredoxin under oxidative stress and reactivated by the glutaredoxin system. J Biol Chem 288: 32241-32247, 2013.

58. Duberley KE, Abramov AY, Chalasani A, Heales SJ, Rahman S, and Hargreaves IP. Human neuronal coenzyme Q10 deficiency results in global loss of mitochondrial respiratory chain activity, increased mitochondrial oxidative stress and reversal of ATP synthase activity: implications for pathogenesis and treatment. $J$ Inherit Metab Dis 36: 63-73, 2013.

59. Fang JG, Nakamura T, Cho DH, Gu ZZ, and Lipton SA. S-nitrosylation of peroxiredoxin 2 promotes oxidative stress-induced neuronal cell death in Parkinson's disease. Proc Natl Acad Sci U S A 104: 18742-18747, 2007.

60. Farina M, Aschner M, and Rocha JBT. Oxidative stress in MeHg-induced neurotoxicity. Toxicol Appl Pharmacol 256: 405-417, 2011.

61. Fernandes AP and Holmgren A. Glutaredoxins: glutathione-dependent redox enzymes with functions far beyond a simple thioredoxin backup system. Antioxid Redox Signal 6: 63-74, 2004.

62. Ferrer-Sueta G, Manta B, Botti H, Radi R, Trujillo M, and Denicola A. Factors affecting protein thiol reactivity and specificity in peroxide reduction. Chem Res Toxicol 24: 434-450, 2011.

63. Findlay VJ, Townsend DM, Morris TE, Fraser JP, He L, and Tew KD. A novel role for human sulfiredoxin in the reversal of glutathionylation. Cancer Res 66: 6800-6806, 2006.

64. Forsmark-Andree P, Persson B, Radi R, Dallner G, and Ernster L. Oxidative modification of nicotinamide nucleotide transhydrogenase in submitochondrial particles: effect of endogenous ubiquinol. Arch Biochem Biophys 336: 113-120, 1996.

65. Forstermann U, Boissel JP, and Kleinert H. Expressional control of the 'constitutive' isoforms of nitric oxide synthase (NOS I and NOS III). FASEB $J$ 12: 773-790, 1998.

66. Frei B, Kim MC, and Ames BN. Ubiquinol-10 is an effective lipid-soluble antioxidant at physiological concentrations. Proc Natl Acad Sci U S A 87: 4879-4883, 1990.

67. Gallogly MM, Shelton MD, Qanungo S, Pai HV, Starke DW, Hoppel CL, Lesnefsky EJ, and Mieyal JJ. Glutaredoxin regulates apoptosis in cardiomyocytes via NFkap$\mathrm{paB}$ targets $\mathrm{Bcl}-2$ and Bcl-xL: implications for cardiac aging. Antioxid Redox Signal 12: 1339-1353, 2010.

68. Gan Y, Ji XM, Hu XM, Luo YM, Zhang LL, Li PY, Liu XR, Yan F, Vosler P, Gao YQ, Stetler RA, and Chen J. Transgenic overexpression of peroxiredoxin-2 attenuates ischemic neuronal injury via suppression of a redox-sensitive prodeath signaling pathway. Antioxid Redox Signal 17: 719732, 2012.

69. Garthwaite J. Concepts of neural nitric oxide-mediated transmission. Eur J Neurosci 27: 2783-2802, 2008.

70. Goedert M, Spillantini MG, Jakes R, Rutherford D, and Crowther RA. Multiple isoforms of human microtubuleassociated protein-Tau - sequences and localization in neurofibrillary tangles of Alzheimers-disease. Neuron 3: 519-526, 1989.

71. Gonzalez-Polo RA, Rodriguez-Martin A, Moran JM, Niso M, Soler G, and Fuentes JM. Paraquat-induced apoptotic cell death in cerebellar granule cells. Brain Res 1011: 170-176, 2004.

72. Gray JP, Heck DE, Mishin V, Smith PJS, Hong JY, Thiruchelvam M, Cory-Slechta DA, Laskin DL, and Laskin JD. Paraquat increases cyanide-insensitive respiration in murine lung epithelial cells by activating an $\mathrm{NAD}(\mathrm{P}) \mathrm{H}$ : paraquat oxidoreductase - identification of the enzyme as thioredoxin reductase. J Biol Chem 282: 79397949, 2007.

73. Greetham D, Vickerstaff J, Shenton D, Perrone GG, Dawes IW, and Grant CM. Thioredoxins function as deglutathionylase enzymes in the yeast Saccharomyces cerevisiae. BMC Biochem 11: 3, 2010.

74. Gutscher M, Sobotta MC, Wabnitz GH, Ballikaya S, Meyer AJ, Samstag Y, and Dick TP. Proximity-based protein thiol oxidation by $\mathrm{H} 2 \mathrm{O} 2$-scavenging peroxidases. J Biol Chem 284: 31532-31540, 2009.

75. Haendeler J, Hoffmann J, Tischler V, Berk BC, Zeiher AM, and Dimmeler S. Redox regulatory and anti-apoptotic functions of thioredoxin depend on S-nitrosylation at cysteine 69. Nat Cell Biol 4: 743-749, 2002. 
76. Halliwell B. Oxidative stress and neurodegeneration: where are we now? J Neurochem 97: 1634-1658, 2006.

77. Hanschmann EM, Lonn ME, Schutte LD, Funke M, Godoy JR, Eitner S, Hudemann C, and Lillig CH. Both thioredoxin 2 and glutaredoxin 2 contribute to the reduction of the mitochondrial 2-Cys peroxiredoxin Prx3. J Biol Chem 285: 40699-40705, 2010.

78. Hara MR, Agrawal N, Kim SF, Cascio MB, Fujimuro M, Ozeki Y, Takahashi M, Cheah JH, Tankou SK, Hester LD, Ferris CD, Hayward SD, Snyder SH, and Sawa A. Snitrosylated GAPDH initiates apoptotic cell death by nuclear translocation following Siah1 binding. Nat Cell Biol 7: 665-674, 2005.

79. Hashemy SI and Holmgren A. Regulation of the catalytic activity and structure of human thioredoxin 1 via oxidation and S-nitrosylation of cysteine residues. J Biol Chem 283: 21890-21898, 2008.

80. Haskew-Layton RE, Payappilly JB, Smirnova NA, Ma TC, Chan KK, Murphy TH, Guo H, Langley B, Sultana R, Butterfield DA, Santagata S, Alldred MJ, Gazaryan IG, Bell GW, Ginsberg SD, and Ratan RR. Controlled enzymatic production of astrocytic hydrogen peroxide protects neurons from oxidative stress via an Nrf2-independent pathway. Proc Natl Acad Sci U S A 107: 17385-17390, 2010.

81. Hendriks WJ, Elson A, Harroch S, Pulido R, Stoker A, and den Hertog J. Protein tyrosine phosphatases in health and disease. FEBS $J$ 280: 708-730, 2013.

82. Hill KE, McCollum GW, Boeglin ME, and Burk RF. Thioredoxin reductase activity is decreased by selenium deficiency. Biochem Biophys Res Commun 234: 293-295, 1997.

83. Holcik M and Korneluk RG. XIAP, the guardian angel. Nat Rev Mol Cell Biol 2: 550-556, 2001.

84. Holmgren A. Thioredoxin. Annu Rev Biochem 54: 237271, 1985.

85. Holmgren A and Lu J. Thioredoxin and thioredoxin reductase: current research with special reference to human disease. Biochem Biophys Res Commun 396: 120-124, 2010.

86. Holmgren A and Sengupta R. The use of thiols by ribonucleotide reductase. Free Radic Biol Med 49: 16171628, 2010.

87. Hwang J, Suh HW, Jeon YH, Hwang E, Nguyen LT, Yeom J, Lee SG, Lee C, Kim KJ, Kang BS, Jeong JO, Oh TK, Choi I, Lee JO, and Kim MH. The structural basis for the negative regulation of thioredoxin by thioredoxininteracting protein. Nat Commun 5: 2958, 2014.

88. Hyson HC, Kieburtz K, Shoulson I, McDermott M, Ravina B, de Blieck EA, Cudkowicz ME, Ferrante RJ, Como P, Frank S, Zimmerman C, Ferrante K, Newhall K, Jennings D, Kelsey T, Walker F, Hunt V, Daigneault S, Goldstein M, Weber J, Watts A, Beal MF, Browne SE, and Metakis LJ. Safety and tolerability of high-dosage coenzyme Q10 in Huntington's disease and healthy subjects. Mov Disord 25: 1924-1928, 2010.

89. Ichinohe A, Kanaumi T, Takashima S, Enokido Y, Nagai $\mathrm{Y}$, and Kimura H. Cystathionine beta-synthase is enriched in the brains of Down's patients. Biochem Biophys Res Commun 338: 1547-1550, 2005.

90. Jellinger KA. Basic mechanisms of neurodegeneration: a critical update. J Cell Mol Med 14: 457-487, 2010.

91. Johansson C, Lillig CH, and Holmgren A. Human mitochondrial glutaredoxin reduces S-glutathionylated proteins with high affinity accepting electrons from either glutathione or thioredoxin reductase. J Biol Chem 279: 7537-7543, 2004.

92. This reference has been deleted.

93. Johnson WM, Golczak M, Choe K, Currran PL, Gorelenkova Miller O, Yao C, Wang W, Lin J, Milkovic NM, Ray A, Ravindranath V, Zhu X, Wilson MA, WilsonDelfosse AL, Chen SG, and Mieyal JJ. Regulation of DJ-1 by glutaredoxin 1 in vivo-implications for Parkinson's disease. Biochemistry, 55: 4519-4532, 2016.

94. Johnson WM, Yao C, Siedlak SL, Wang WZ, Zhu XW, Caldwell GA, Wilson-Delfosse AL, Mieyal JJ, and Chen SG. Glutaredoxin deficiency exacerbates neurodegeneration in C. elegans models of Parkinson's disease. Hum Mol Genet 24: 1322-1335, 2015.

95. Jones DP. Redefining oxidative stress. Antioxid Redox Signal 8: 1865-1879, 2006.

96. Ju Y, Wu L, and Yang G. Thioredoxin 1 regulation of protein S-desulfhydration. Biochem Biophys Rep 5: 27-34, 2016.

97. Kang Y, Viswanath V, Jha N, Qiao X, Mo JQ, and Andersen JK. Brain gamma-glutamyl cysteine synthetase (GCS) mRNA expression patterns correlate with regionalspecific enzyme activities and glutathione levels. $\mathrm{J} \mathrm{Neu-}$ rosci Res 58: 436-441, 1999.

98. Kaur P, Aschner M, and Syversen T. Glutathione modulation influences methyl mercury induced neurotoxicity in primary cell cultures of neurons and astrocytes. Neurotoxicology 27: 492-500, 2006.

99. Kelleher ZT, Matsumoto A, Stamler JS, and Marshall HE. NOS2 regulation of NF-kappaB by S-nitrosylation of $\mathrm{p} 65$. J Biol Chem 282: 30667-30672, 2007.

100. Kemmerling U, Munoz P, Muller M, Sanchez G, Aylwin ML, Klann E, Carrasco MA, and Hidalgo C. Calcium release by ryanodine receptors mediates hydrogen peroxide-induced activation of ERK and CREB phosphorylation in N2a cells and hippocampal neurons. Cell Calcium 41: 491-502, 2007.

101. Kenchappa RS and Ravindranath V. Glutaredoxin is essential for maintenance of brain mitochondrial complex I: studies with MPTP. FASEB J 17: 717-719, 2003.

102. Kil IS and Park JW. Regulation of mitochondrial $\mathrm{NADP}(+)$-dependent isocitrate dehydrogenase activity by glutathionylation. J Biol Chem 280: 10846-10854, 2005.

103. Kimura Y, Goto Y, and Kimura H. Hydrogen sulfide increases glutathione production and suppresses oxidative stress in mitochondria. Antioxid Redox Signal 12: 1-13, 2010.

104. Krapfenbauer K, Engidawork E, Cairns N, Fountoulakis $\mathrm{M}$, and Lubec G. Aberrant expression of peroxiredoxin subtypes in neurodegenerative disorders. Brain Res 967: 152-160, 2003.

105. Krishnan N, Fu C, Pappin DJ, and Tonks NK. H2SInduced sulfhydration of the phosphatase PTP1B and its role in the endoplasmic reticulum stress response. Sci Signal 4: ra86, 2011.

106. This reference has been deleted.

107. Kwong LK, Kamzalov S, Rebrin I, Bayne AC, Jana CK, Morris P, Forster MJ, and Sohal RS. Effects of coenzyme $\mathrm{Q}(10)$ administration on its tissue concentrations, mitochondrial oxidant generation, and oxidative stress in the rat. Free Radic Biol Med 33: 627-638, 2002.

108. Lakshmi BVS, Sudhakar M, and Prakash KS. Protective effect of selenium against aluminum chloride-induced 
Alzheimer's disease: behavioral and biochemical alterations in rats. Biol Trace Elem Res 165: 67-74, 2015.

109. Laurent TC, Moore EC, and Reichard P. Enzymatic synthesis of deoxyribonucleotides. Iv. Isolation and characterization of thioredoxin, the hydrogen donor from Escherichia coli B. J Biol Chem 239: 3436-3444, 1964.

110. Leak RK, Zhang LL, Luo YM, Li PY, Zhao HP, Liu XR, Ling F, Jia JP, Chen J, and Ji XM. Peroxiredoxin 2 battles poly(ADP-ribose) polymerase 1-and p53-dependent prodeath pathways after ischemic injury. Stroke 44: 1124-1134, 2013.

111. Lee BC, Dikiy A, Kim HY, and Gladyshev VN. Functions and evolution of selenoprotein methionine sulfoxide reductases. Biochim Biophys Acta 1790: 1471-1477, 2009.

112. Lee H, Yi JS, Lawan A, Min K, and Bennett AM. Mining the function of protein tyrosine phosphatases in health and disease. Semin Cell Dev Biol 37: 66-72, 2015.

113. Lee SR, Kwon KS, Kim SR, and Rhee SG. Reversible inactivation of protein-tyrosine phosphatase 1B in A431 cells stimulated with epidermal growth factor. $\mathrm{J} \mathrm{Biol}$ Chem 273: 15366-15372, 1998.

114. Li F, Sonveaux P, Rabbani ZN, Liu SL, Yan B, Huang Q, Vujaskovic Z, Dewhirst MW, and Li CY. Regulation of HIF-1 alpha stability through S-nitrosylation. Mol Cell 26: 63-74, 2007.

115. Lin MT and Beal MF. Mitochondrial dysfunction and oxidative stress in neurodegenerative diseases. Nature 443: 787-795, 2006.

116. Lipton SA, Choi YB, Takahashi H, Zhang DX, Li WZ, Godzik A, and Bankston LA. Cysteine regulation of protein function-as exemplified by NMDA-receptor modulation. Trends Neurosci 25: 474-480, 2002.

117. Ljubisavljevic S, Stojanovic I, Cvetkovic T, Vojinovic S, Stojanov D, Stojanovic D, Bojanic V, Stokanovic D, and Pavlovic D. Glutathione homeostasis disruption of erythrocytes, but not glutathione peroxidase activity change, is closely accompanied with neurological and radiological scoring of acute CNS inflammation. Neuroimmunomodulation 21: 13-20, 2014.

118. Lopert P, Day BJ, and Patel M. Thioredoxin reductase deficiency potentiates oxidative stress, mitochondrial dysfunction and cell death in dopaminergic cells. PLoS One 7: e50683, 2012.

119. Lopert $\mathrm{P}$ and Patel M. Nicotinamide nucleotide transhydrogenase (Nnt) links the substrate requirement in brain mitochondria for hydrogen peroxide removal to the thioredoxin/peroxiredoxin (Trx/Prx) system. J Biol Chem 289: 15611-15620, 2014.

120. Lovell MA, Xie C, Gabbita SP, and Markesbery WR. Decreased thioredoxin and increased thioredoxin reductase levels in Alzheimer's disease brain. Free Radic Biol Med 28: 418-427, 2000.

121. Lu J and Holmgren A. Selenoproteins. J Biol Chem 284: 723-727, 2009.

122. Lu $\mathrm{J}$ and Holmgren A. The thioredoxin antioxidant system. Free Radic Biol Med 66: 75-87, 2014.

123. Lu J, Zhong L, Lonn ME, Burk RF, Hill KE, and Holmgren A. Penultimate selenocysteine residue replaced by cysteine in thioredoxin reductase from seleniumdeficient rat liver. FASEB J 23: 2394-2402, 2009.

124. Lundberg M, Johansson C, Chandra J, Enoksson M, Jacobsson G, Ljung J, Johansson $\mathrm{M}$, and Holmgren A. Cloning and expression of a novel human glutaredoxin
(Grx2) with mitochondrial and nuclear isoforms. $J$ Biol Chem 276: 26269-26275, 2001.

125. Luthman $M$ and Holmgren A. Rat liver thioredoxin and thioredoxin reductase: purification and characterization. Biochemistry 21: 6628-6633, 1982.

126. Madrigal JL, Olivenza R, Moro MA, Lizasoain I, Lorenzo P, Rodrigo J, and Leza JC. Glutathione depletion, lipid peroxidation and mitochondrial dysfunction are induced by chronic stress in rat brain. Neuropsychopharmacology 24: 420-429, 2001.

127. Martin JL. Thioredoxin - a fold for all reasons. Structure 3: 245-250, 1995.

128. Masaki C, Sharpley AL, Godlewska BR, Berrington A, Hashimoto T, Singh N, Vasudevan SR, Emir UE, Churchill GC, and Cowen PJ. Effects of the potential lithium-mimetic, ebselen, on brain neurochemistry: a magnetic resonance spectroscopy study at 7 tesla. Psychopharmacology 233: 1097-1104, 2016.

129. Mattson MP and Magnus T. Ageing and neuronal vulnerability. Nat Rev Neurosci 7: 278-294, 2006.

130. Maurya PK, Noto C, Rizzo LB, Rios AC, Nunes SOV, Barbosa DS, Sethi S, Zeni M, Mansur RB, Maes M, and Brietzke E. The role of oxidative and nitrosative stress in accelerated aging and major depressive disorder. Prog Neuropsychopharmacol Biol Psychiatry 65: 133-144, 2016.

131. Mayer B, John M, and Bohme E. Purification of a $\mathrm{Ca} 2+/$ calmodulin-dependent nitric oxide synthase from porcine cerebellum. Cofactor-role of tetrahydrobiopterin. FEBS Lett 277: 215-219, 1990.

132. McCarthy S, Somayajulu M, Sikorska M, BorowyBorowski $\mathrm{H}$, and Pandey S. Paraquat induces oxidative stress and neuronal cell death; neuroprotection by watersoluble Coenzyme Q10. Toxicol Appl Pharmacol 201: 2131, 2004.

133. Mieyal JJ, Gallogly MM, Qanungo S, Sabens EA, and Shelton MD. Molecular mechanisms and clinical implications of reversible protein S-glutathionylation. Antioxid Redox Signal 10: 1941-1988, 2008.

134. Mikami Y, Shibuya N, Kimura Y, Nagahara N, Ogasawara $\mathrm{Y}$, and Kimura $\mathrm{H}$. Thioredoxin and dihydrolipoic acid are required for 3-mercaptopyruvate sulfurtransferase to produce hydrogen sulfide. Biochem J 439: 479-485, 2011.

135. Mir S, Sen T, and Sen N. Cytokine-induced GAPDH sulfhydration affects PSD95 degradation and memory. Mol Cell 56: 786-795, 2014.

136. Mitchell DA and Marletta MA. Thioredoxin catalyzes the S-nitrosation of the caspase-3 active site cysteine. Nat Chem Biol 1: 154-158, 2005.

137. Mitsui A, Hamuro J, Nakamura H, Kondo N, Hirabayashi Y, Ishizaki-Koizumi S, Hirakawa T, Inoue T, and Yodoi J. Overexpression of human thioredoxin in transgenic mice controls oxidative stress and life span. Antioxid Redox Signal 4: 693-696, 2002.

138. Murphy MP. How mitochondria produce reactive oxygen species. Biochem J 417: 1-13, 2009.

139. Musik I, Kielczykowska M, and Kocot J. Oxidant balance in brain of rats receiving different compounds of selenium. Biometals 26: 763-771, 2013.

140. Mustafa AK, Gadalla MM, Sen N, Kim S, Mu WT, Gazi SK, Barrow RK, Yang GD, Wang R, and Snyder SH. H2S signals through protein S-sulfhydration. Sci Signal 2: ra72, 2009.

141. Mustafa AK, Kumar M, Selvakumar B, Ho GP, Ehmsen JT, Barrow RK, Amzel LM, and Snyder SH. Nitric oxide 
S-nitrosylates serine racemase, mediating feedback inhibition of D-serine formation. Proc Natl Acad Sci U S A 104: 2950-2955, 2007.

142. Nair PMG and Choi J. Characterization and transcriptional regulation of thioredoxin reductase 1 on exposure to oxidative stress inducing environmental pollutants in Chironomus riparius. Comp Biochem Physiol B Biochem Mol Biol 161: 134-139, 2012.

143. Nakajima H, Amano W, Fujita A, Fukuhara A, Azuma YT, Hata F, Inui T, and Takeuchi T. The active site cysteine of the proapoptotic protein glyceraldehyde-3-phosphate dehydrogenase is essential in oxidative stress-induced aggregation and cell death. J Biol Chem 282: 26562-26564, 2007.

144. Newman SF, Sultana R, Perluigi M, Coccia R, Cai J, Pierce WM, Klein JB, Turner DM, and Butterfield DA. An increase in S-glutathionylated proteins in the Alzheimer's disease inferior parietal lobule, a proteomics approach. $J$ Neurosci Res 85: 1506-1514, 2007.

145. Ni MW, Li X, Yin ZB, Sidoryk-Wegrzynowicz M, Jiang HY, Farina M, Rocha JBT, Syversen T, and Aschner M. Comparative study on the response of rat primary astrocytes and microglia to methylmercury toxicity. Glia 59: 810-820, 2011.

146. Nishitoh H, Matsuzawa A, Tobiume K, Saegusa K, Takeda K, Inoue K, Hori S, Kakizuka A, and Ichijo H. ASK1 is essential for endoplasmic reticulum stress-induced neuronal cell death triggered by expanded polyglutamine repeats. Genes Dev 16: 1345-1355, 2002.

147. Nishiyama A, Matsui M, Iwata S, Hirota K, Masutani H, Nakamura H, Takagi Y, Sono H, Gon Y, and Yodoi J. Identification of thioredoxin-binding protein-2/vitamin $\mathrm{D}(3)$ up-regulated protein 1 as a negative regulator of thioredoxin function and expression. J Biol Chem 274: 21645-21650, 1999.

148. Olivera GC, Ren X, Vodnala SK, Lu J, Coppo L, Leepiyasakulchai C, Holmgren A, Kristensson K, and Rottenberg ME. Nitric oxide protects against infectioninduced neuroinflammation by preserving the stability of the blood-brain barrier. PLoS Pathog 12: e1005442, 2016.

149. Oslowski CM, Hara T, O’Sullivan-Murphy B, Kanekura K, Lu S, Hara M, Ishigaki S, Zhu LJ, Hayashi E, Hui ST, Greiner D, Kaufman RJ, Bortell R, and Urano F. Thioredoxininteracting protein mediates ER stress-induced beta cell death through initiation of the inflammasome. Cell Metab 16: 265-273, 2012.

150. Papadia S, Soriano FX, Leveille F, Martel MA, Dakin KA, Hansen HH, Kaindl A, Sifringer M, Fowler J, Stefovska V, McKenzie G, Craigon M, Corriveau R, Ghazal P, Horsburgh K, Yankner BA, Wyllie DJ, Ikonomidou C, and Hardingham GE. Synaptic NMDA receptor activity boosts intrinsic antioxidant defenses. Nat Neurosci 11: 476-487, 2008.

151. Papp LV, Lu J, Holmgren A, and Khanna KK. From selenium to selenoproteins: synthesis, identity, and their role in human health. Antioxid Redox Signal 9: 775-806, 2007.

152. This reference has been deleted.

153. Pastore A, Tozzi G, Gaeta LM, Bertini E, Serafini V, Di Cesare S, Bonetto V, Casoni F, Carrozzo R, Federici G, and Piemonte F. Actin glutathionylation increases in fibroblasts of patients with Friedreich's ataxia-a potential role in the pathogenesis of the disease. J Biol Chem 278: 42588-42595, 2003.

154. Patra RC, Swarup D, and Dwivedi SK. Antioxidant effects of alpha tocopherol, ascorbic acid and L-methionine on lead induced oxidative stress to the liver, kidney and brain in rats. Toxicology 162: 81-88, 2001.

155. Peltoniemi MJ, Karala AR, Jurvansuu JK, Kinnula VL, and Ruddock LW. Insights into deglutathionylation reactions-different intermediates in the glutaredoxin and protein disulfide isomerase catalyzed reactions are defined by the gamma-linkage present in glutathione. J Biol Chem 281: 33107-33114, 2006.

156. Peng XX, Xu JQ, and Arner ESJ. Thiophosphate and selenite conversely modulate cell death induced by glutathione depletion or cisplatin: effects related to activity and Sec contents of thioredoxin reductase. Biochem J 447: 167-174, 2012.

157. Perry TL, Yong VW, Bergeron C, Hansen S, and Jones K. Amino acids, glutathione, and glutathione transferase activity in the brains of patients with Alzheimer's disease. Ann Neurol 21: 331-336, 1987.

158. Peskin AV, Pace PE, Behring JB, Paton LN, Soethoudt M, Bachschmid MM, and Winterbourn CC. Glutathionylation of the active site cysteines of peroxiredoxin 2 and recycling by glutaredoxin. J Biol Chem 291: 3053-3062, 2016.

159. Peters GH, Frimurer TM, and Olsen OH. Electrostatic evaluation of the signature motif $(\mathrm{H} / \mathrm{V}) \mathrm{CX} 5 \mathrm{R}(\mathrm{S} / \mathrm{T})$ in protein-tyrosine phosphatases. Biochemistry 37: 53835393, 1998.

160. Pirazzini M, Azarnia Tehran D, Zanetti G, Megighian A, Scorzeto M, Fillo S, Shone CC, Binz T, Rossetto O, Lista $\mathrm{F}$, and Montecucco $\mathrm{C}$. Thioredoxin and its reductase are present on synaptic vesicles, and their inhibition prevents the paralysis induced by botulinum neurotoxins. Cell Rep 8: 1870-1878, 2014.

161. Pollock JS, Forstermann U, Mitchell JA, Warner TD, Schmidt HH, Nakane M, and Murad F. Purification and characterization of particulate endothelium-derived relaxing factor synthase from cultured and native bovine aortic endothelial cells. Proc Natl Acad Sci U S A 88: 10480-10484, 1991.

162. Radyuk SN, Sohal RS, and Orr WC. Thioredoxin peroxidases can foster cytoprotection or cell death in response to different stressors: over- and under-expression of thioredoxin peroxidase in Drosophila cells. Biochem $J$ 371: 743-752, 2003.

163. Ramassamy C, Averill D, Beffert U, Theroux L, LussierCacan S, Cohn JS, Christen Y, Schoofs A, Davignon J, and Poirier J. Oxidative insults are associated with apolipoprotein E genotype in Alzheimer's disease brain. Neurobiol Dis 7: 23-37, 2000.

164. Ranjbar A, Pasalar P, Sedighi A, and Abdollahi M. Induction of oxidative stress in paraquat formulating workers. Toxicol Lett 131: 191-194, 2002.

165. Reilly C. Selenium in Food and Health. New York: Springer, 2006, xvi, p. 206.

166. Rodrigues J, Branco V, Lu J, Holmgren A, and Carvalho C. Toxicological effects of thiomersal and ethylmercury: inhibition of the thioredoxin system and NADP(+)dependent dehydrogenases of the pentose phosphate pathway. Toxicol Appl Pharmacol 286: 216-223, 2015.

167. Roede JR, Hansen JM, Go YM, and Jones DP. Maneb and paraquat-mediated neurotoxicity: involvement of peroxiredoxin/thioredoxin system. Toxicol Sci 121: 368-375, 2011.

168. Romagnoli A, Oradei A, Destito C, Iacocagni A, Marin AW, and Littarru GP. Protective role in vivo of coenzyme 
Q10 during reperfusion of ischemic limbs. Mol Aspects Med 15 Suppl: s177-s185, 1994.

169. Rooney JPK. The role of thiols, dithiols, nutritional factors and interacting ligands in the toxicology of mercury. Toxicology 234: 145-156, 2007.

170. Sandalova T, Zhong L, Lindqvist Y, Holmgren A, and Schneider G. Three-dimensional structure of a mammalian thioredoxin reductase: implications for mechanism and evolution of a selenocysteine-dependent enzyme. Proc Natl Acad Sci U S A 98: 9533-9538, 2001.

171. Santa Maria C and Machado A. Effects of development and ageing on pulmonary NADPH-cytochrome c reductase, glutathione peroxidase, glutathione reductase and thioredoxin reductase activities in male and female rats. Mech Ageing Dev 37: 183-195, 1986.

172. Sarafian TA, Verity MA, Vinters HV, Shih CCY, Shi LR, Ji XD, Dong LP, and Shau HY. Differential expression of peroxiredoxin subtypes in human brain cell types. $J$ Neurosci Res 56: 206-212, 1999.

173. Sarkar S, Korolchuk VI, Renna M, Imarisio S, Fleming A, Williams A, Garcia-Arencibia M, Rose C, Luo S, Underwood BR, Kroemer G, O'Kane CJ, and Rubinsztein DC. Complex inhibitory effects of nitric oxide on autophagy. Mol Cell 43: 19-32, 2011.

174. Schilling G, Coonfield ML, Ross CA, and Borchelt DR. Coenzyme Q10 and remacemide hydrochloride ameliorate motor deficits in a Huntington's disease transgenic mouse model. Neurosci Lett 315: 149-153, 2001.

175. Schulz JB, Lindenau J, Seyfried J, and Dichgans J. Glutathione, oxidative stress and neurodegeneration. Eur $J$ Biochem 267: 4904-4911, 2000.

176. Sen N, Paul BD, Gadalla MM, Mustafa AK, Sen T, Xu R, Kim S, and Snyder SH. Hydrogen sulfide-linked sulfhydration of NF-kappaB mediates its antiapoptotic actions. Mol Cell 45: 13-24, 2012.

177. Shimizu K, Matsubara K, Ohtaki K, Fujimaru S, Saito O, and Shiono H. Paraquat induces long-lasting dopamine overflow through the excitotoxic pathway in the striatum of freely moving rats. Brain Res 976: 243-252, 2003.

178. Sian J, Dexter DT, Lees AJ, Daniel S, Jenner P, and Marsden CD. Glutathione-related enzymes in brain in Parkinson's disease. Ann Neurol 36: 356-361, 1994.

179. Silva-Adaya D, Gonsebatt ME, and Guevara J. Thioredoxin system regulation in the central nervous system: experimental models and clinical evidence. Oxid Med Cell Longev 2014: 590808, 2014.

180. Sinet PM, Heikkila RE, and Cohen G. Hydrogen peroxide production by rat brain in vivo. $J$ Neurochem 34: 1421 1428, 1980.

181. Somayajulu M, McCarthy S, Hung M, Sikorska M, Borowy-Borowski H, and Pandey S. Role of mitochondria in neuronal cell death induced by oxidative stress; neuroprotection by coenzyme Q(10). Neurobiol Dis 18: 618627, 2005.

182. Sparaco M, Gaeta LM, Tozzi G, Bertini E, Pastore A, Simonati A, Santorelli FM, and Piemonte F. Protein glutathionylation in human central nervous system: potential role in redox regulation of neuronal defense against free radicals. J Neurosci Res 83: 256-263, 2006.

183. Sreekala $S$ and Indira M. Impact of co administration of selenium and quinolinic acid in the rat's brain. Brain Res 1281: 101-107, 2009.

184. Starkov AA, Andreyev AY, Zhang SF, Starkova NN, Korneeva M, Syromyatnikov M, and Popov VN. Scavenging of
$\mathrm{H} 2 \mathrm{O} 2$ by mouse brain mitochondria. $J$ Bioenerg Biomembr 46: 471-477, 2014.

185. Stone JR and Yang S. Hydrogen peroxide: a signaling messenger. Antioxid Redox Signal 8: 243-270, 2006.

186. Sun N, Hao JR, Li XY, Yin XH, Zong YY, Zhang GY, and Gao C. GluR6-FasL-Trx2 mediates denitrosylation and activation of procaspase-3 in cerebral ischemia/reperfusion in rats. Cell Death Dis 4: e771, 2013.

187. Sundaresan M, Yu ZX, Ferrans VJ, Irani K, and Finkel T. Requirement for generation of $\mathrm{H} 2 \mathrm{O} 2$ for platelet-derived growth factor signal transduction. Science 270: 296-299, 1995.

188. Takizawa M, Komori K, Tampo $\mathrm{Y}$, and Yonaha $\mathrm{M}$. Paraquat-induced oxidative stress and dysfunction of cellular redox systems including antioxidative defense enzymes glutathione peroxidase and thioredoxin reductase. Toxicol In Vitro 21: 355-363, 2007.

189. Tampo Y, Tsukamoto M, and Yonaha M. Superoxide production from paraquat evoked by exogenous NADPH in pulmonary endothelial cells. Free Radic Biol Med 27: 588-595, 1999.

190. Taylor ER, Hurrell F, Shannon RJ, Lin TK, Hirst J, and Murphy MP. Reversible glutathionylation of complex I increases mitochondrial superoxide formation. $J$ Biol Chem 278: 19603-19610, 2003.

191. Tenneti L, D'Emilia DM, and Lipton SA. Suppression of neuronal apoptosis by S-nitrosylation of caspases. Neurosci Lett 236: 139-142, 1997.

192. Tomasetti M, Alleva R, Borghi B, and Collins AR. In vivo supplementation with coenzyme Q10 enhances the recovery of human lymphocytes from oxidative DNA damage. FASEB J 15: 1425-1427, 2001.

193. Tong J, Fitzmaurice PS, Moszczynska A, Mattina K, Ang L-C, Boileau I, Furukawa Y, Sailasuta N, and Kish SJ. Do glutathione levels decline in aging human brain? Free Radic Biol Med 93: 110-117, 2016.

194. Tonks NK, Yang Q, and Guida P, Jr. Structure, regulation, and function of protein tyrosine phosphatases. Cold Spring Harbor Symp Quant Biol 56: 265-273, 1991.

195. Tretter L, Sipos I, and Adam-Vizi V. Initiation of neuronal damage by complex I deficiency and oxidative stress in Parkinson's disease. Neurochem Res 29: 569577, 2004.

196. Tsang AH, Lee YI, Ko HS, Savitt JM, Pletnikova O, Troncoso JC, Dawson VL, Dawson TM, and Chung KK. S-nitrosylation of XIAP compromises neuronal survival in Parkinson's disease. Proc Natl Acad Sci U S A 106: 49004905, 2009.

197. Tsuda M, Ootaka R, Ohkura C, Kishita Y, Seong KH, Matsuo T, and Aigaki T. Loss of Trx-2 enhances oxidative stress-dependent phenotypes in Drosophila. FEBS Lett 584: 3398-3401, 2010.

198. Tsukamoto M, Tampo Y, Sawada M, and Yonaha M. Paraquat-induced oxidative stress and dysfunction of the glutathione redox cycle in pulmonary microvascular endothelial cells. Toxicol Appl Pharmacol 178: 82-92, 2002.

199. Uehara T, Nakamura T, Yao DD, Shi ZQ, Gu ZZ, Ma YL, Masliah E, Nomura Y, and Lipton SA. S-Nitrosylated protein-disulphide isomerase links protein misfolding to neurodegeneration. Nature 441: 513-517, 2006.

200. Um HC, Jang JH, Kim DH, Lee C, and Surh YJ. Nitric oxide activates Nrf2 through S-nitrosylation of Keap1 in PC12 cells. Nitric Oxide Biol Chem 25: 161-168, 2011. 
201. Vahter M, Mottet NK, Friberg L, Lind B, Shen DD, and Burbacher T. Speciation of mercury in the primate blood and brain following long-term exposure to methyl mercury. Toxicol Appl Pharmacol 124: 221-229, 1994.

202. Vandiver MS, Paul BD, Xu RS, Karuppagounder S, Rao F, Snowman AM, Ko HS, Il Lee Y, Dawson VL, Dawson TM, Sen N, and Snyder SH. Sulfhydration mediates neuroprotective actions of parkin. Nat Commun 4: 1626, 2013.

203. Velu CS, Niture SK, Doneanu CE, Pattabiraman N, and Srivenugopal KS. Human p53 is inhibited by glutathionylation of cysteines present in the proximal DNAbinding domain during oxidative stress. Biochemistry 46: 7765-7780, 2007.

204. Waly M, Power-Charnitsky VA, Hodgson N, Sharma A, Audhya T, Zhang Y, and Deth R. Alternatively spliced methionine synthase in SH-SY5Y neuroblastoma cells: cobalamin and GSH dependence and inhibitory effects of neurotoxic metals and thimerosal. Oxid Med Cell Longev 2016: 6143753, 2016.

205. Wedmann R, Onderka C, Wei S, Szijarto IA, Miljkovic JL, Mitrovic A, Lange M, Savitsky S, Yadav PK, Torregrossa R, Harrer EG, Harrer T, Ishii I, Gollasch M, Wood ME, Galardon E, Xian M, Whiteman M, Banerjee R, and Filipovic MR. Improved tag-switch method reveals that thioredoxin acts as depersulfidase and controls the intracellular levels of protein persulfidation. Chem Sci 7: 34143426, 2016.

206. Weichsel A, Brailey JL, and Montfort WR. Buried Snitrosocysteine revealed in crystal structures of human thioredoxin. Biochemistry 46: 1219-1227, 2007.

207. Winterbourn CC and Hampton MB. Thiol chemistry and specificity in redox signaling. Free Radic Biol Med 45: 549-561, 2008.

208. Woo HA, Yim SH, Shin DH, Kang D, Yu DY, and Rhee SG. Inactivation of peroxiredoxin I by phosphorylation allows localized $\mathrm{H}(2) \mathrm{O}(2)$ accumulation for cell signaling. Cell 140: 517-528, 2010.

209. Wu C, Liu T, Chen W, Oka S, Fu C, Jain MR, Parrott AM, Baykal AT, Sadoshima J, and Li H. Redox regulatory mechanism of transnitrosylation by thioredoxin. Mol Cell Proteomics: MCP 9: 2262-2275, 2010.

210. Wu C, Parrott AM, Liu T, Jain MR, Yang Y, Sadoshima J, and $\mathrm{Li} \mathrm{H}$. Distinction of thioredoxin transnitrosylation and denitrosylation target proteins by the ICAT quantitative approach. J Proteomics 74: 2498-2509, 2011.

211. Xia L, Nordman T, Olsson JM, Damdimopoulos A, Bjorkhem-Bergman L, Nalvarte I, Eriksson LC, Arner ES, Spyrou G, and Bjornstedt M. The mammalian cytosolic selenoenzyme thioredoxin reductase reduces ubiquinone. A novel mechanism for defense against oxidative stress. $J$ Biol Chem 278: 2141-2146, 2003.

212. Xie ZZ, Shi MM, Xie L, Wu ZY, Li G, Hua F, and Bian JS. Sulfhydration of p66Shc at cysteine59 mediates the antioxidant effect of hydrogen sulfide. Antioxid Redox Signal 21: 2531-2542, 2014.

213. Xu C, Bailly-Maitre B, and Reed JC. Endoplasmic reticulum stress: cell life and death decisions. J Clin Invest 115: 2656-2664, 2005.

214. Yamaguchi T, Sano K, Takakura K, Saito I, Shinohara Y, Asano T, Yasuhara H, and Grp ES. Ebselen in acute ischemic stroke-a placebo-controlled, double-blind clinical trial. Stroke 29: 12-17, 1998.
215. Yang G, Zhao K, Ju Y, Mani S, Cao Q, Puukila S, Khaper N, $\mathrm{Wu}$ L, and Wang R. Hydrogen sulfide protects against cellular senescence via S-sulfhydration of Keap1 and activation of Nrf2. Antioxid Redox Signal 18: 1906-1919, 2013.

216. Yang W, Tiffany-Castiglioni E, Lee MY, and Son IH. Paraquat induces cyclooxygenase-2 (COX-2) implicated toxicity in human neuroblastoma SH-SY5Y cells. Toxicol Lett 199: 239-246, 2010.

217. Yao D, Gu Z, Nakamura T, Shi ZQ, Ma Y, Gaston B, Palmer LA, Rockenstein EM, Zhang Z, Masliah E, Uehara $\mathrm{T}$, and Lipton SA. Nitrosative stress linked to sporadic Parkinson's disease: S-nitrosylation of parkin regulates its E3 ubiquitin ligase activity. Proc Natl Acad Sci U S A 101: 10810-10814, 2004.

218. Yasinska IM and Sumbayev VV. S-nitrosation of Cys-800 of HIF-1alpha protein activates its interaction with p300 and stimulates its transcriptional activity. FEBS Lett 549: 105-109, 2003.

219. Yeh ST, Guo HR, Su YS, Lin HJ, Hou CC, Chen HM, Chang MC, and Wang YJ. Protective effects of Nacetylcysteine treatment post acute paraquat intoxication in rats and in human lung epithelial cells. Toxicology 223: 181-190, 2006.

220. Zemolin APP, Meinerz DF, de Paula MT, Mariano DOC, Rocha JBT, Pereira AB, Posser T, and Franco JL. Evidences for a role of glutathione peroxidase $4(\mathrm{GPx} 4)$ in methylmercury induced neurotoxicity in vivo. Toxicology 302: 60-67, 2012.

221. Zhang H, Du Y, Zhang X, Lu J, and Holmgren A. Glutaredoxin 2 reduces both thioredoxin 2 and thioredoxin 1 and protects cells from apoptosis induced by auranofin and 4hydroxynonenal. Antioxid Redox Signal 21: 669-681, 2014.

222. Zhang R, Al-Lamki R, Bai L, Streb JW, Miano JM, Bradley $\mathrm{J}$, and Min W. Thioredoxin-2 inhibits mitochondria-located ASK1-mediated apoptosis in a JNK-independent manner. Circ Res 94: 1483-1491, 2004.

223. Zhang Y, Zhou Y, Schweizer U, Savaskan NE, Hua D, Kipnis J, Hatfield DL, and Gladyshev VN. Comparative analysis of selenocysteine machinery and selenoproteome gene expression in mouse brain identifies neurons as key functional sites of selenium in mammals. $J$ Biol Chem 283: 2427-2438, 2008.

224. Zhong L and Holmgren A. Essential role of selenium in the catalytic activities of mammalian thioredoxin reductase revealed by characterization of recombinant enzymes with selenocysteine mutations. J Biol Chem 275: 1812118128, 2000.

Address correspondence to: Dr. Jun Lu School of Pharmaceutical Sciences Southwest University Chongqing 400715

China

E-mail: jun.lu@ki.se,junlu@swu.edu.cn

Date of first submission to ARS Central, October 27, 2016; date of final revised submission, April 13, 2017; date of acceptance, April 14, 2017. 


\section{Abbreviations Used}

$\mathrm{AChE}=$ acetylcholinesterase

$\mathrm{AD}=$ Alzheimer's disease

ASK1 = apoptosis-signaling kinase 1

$\mathrm{A} \beta=\beta$-amyloid protein

$\mathrm{BBB}=$ blood-brain barrier

$\mathrm{CAT}=$ catalase

$\mathrm{CBS}=$ cystathionine $\beta$-synthase

cGMP $=$ cyclic guanosine monophosphate

$\mathrm{CNS}=$ central nervous system

CoQ10 $=$ coenzyme $\mathrm{Q} 10$

$\mathrm{CREB}=\mathrm{cAMP} / \mathrm{Ca}^{2+}$ response element binding protein

Drp1 = dynamin-related protein 1

$\mathrm{DS}=$ Down's syndrome

eNOS $=$ endothelial NOS

$\mathrm{ER}=$ endoplasmic reticulum

$\mathrm{EtHg}=$ ethylmercury

GABA $=\gamma$-aminobutyric acid

GluR6 $=$ glutamate receptor 6

$\mathrm{GPx}=$ glutathione peroxidase

$\mathrm{GR}=$ glutathione reductase

$\mathrm{GSH}=$ glutathione

GST $=$ GSH-S-transferase

$\mathrm{H}_{2} \mathrm{O}_{2}=$ hydrogen peroxide

$\mathrm{H}_{2} \mathrm{~S}=$ hydrogen sulfide

$\mathrm{HD}=$ Huntington's disease

HIF-1 = hypoxia-inducible factor 1

$\mathrm{I} / \mathrm{R}=$ ischemia/reperfusion

$\mathrm{IDPm}=$ mitochondrial NADP+-dependent isocitrate dehydrogenase

IMPase $=$ inositol monophosphatase

iNOS $=$ inducible NOS

Keap1 = Klech-like ECH-associated protein 1

LPS = lipopolysaccharide

LTP $=$ long-term potentiation

$\mathrm{MAO}=$ monoamine oxidase
MAP3K $=$ mitogen-activated protein kinase kinase kinase

$\mathrm{MeHg}=$ methylmercury

MPTP = 1-methyl-4-phenyl-1,2,3,6tetrahydropyridine

MSR $=$ methionine sulfoxide reductase

NMDA $=$ N-methyl-D-aspartate

$\mathrm{nNOS}=$ neuronal NOS

$\mathrm{Nnt}=$ nicotinamide nucleotide transhydrogenase

$\mathrm{NO}=$ nitric oxide

$\mathrm{NOS}=$ nitric oxide synthase

$\mathrm{NOX}=\mathrm{NADPH}$ oxidase

$\mathrm{Nrf2}=$ nuclear factor E2-related factor 2

PARP1 $=$ poly (ADP-ribose $)$ polymerase 1

$\mathrm{PD}=$ Parkinson's disease

$\mathrm{PDI}=$ protein disulfide isomerase

$\mathrm{PQ}=$ paraquat

$\operatorname{Prx}=$ peroxiredoxin

PSD95 $=$ postsynaptic density 95

PTKs $=$ protein tyrosine kinases

PTM $=$ post-translational modification

PTPs $=$ protein tyrosine phosphatases

$\mathrm{RNR}=$ ribonucleotide reductase

$\mathrm{RNS}=$ reactive nitrogen species

ROS $=$ reactive oxygen species

RPS3 = ribosomal protein S3

$\mathrm{RyR}=$ ryanodine receptors

$\mathrm{Se}=$ selenium

$\mathrm{SOD}=$ superoxide dismutase

TCA $=$ tricarboxylic acid cycle

TRP14 $=$ Trx-related protein of $14-\mathrm{kDa}$

$\operatorname{Trx}=$ thioredoxin

$\operatorname{TrxR}=$ thioredoxin reductase

TXNIP $=$ thioredoxin-interacting protein

$\mathrm{XIAP}=\mathrm{X}$-linked inhibitor of apoptosis protein

$\gamma$-GCS $=\gamma$-glutamyl cysteine synthetase 